San Jose State University

SJSU ScholarWorks

Master's Theses

Master's Theses and Graduate Research

Spring 2016

\title{
Evaluating the Predictive Validity of the Global Competencies Inventory for Determining Global Leadership Outcomes
}

\author{
Emily Tuyet Le \\ San Jose State University
}

Follow this and additional works at: https://scholarworks.sjsu.edu/etd_theses

\section{Recommended Citation}

Le, Emily Tuyet, "Evaluating the Predictive Validity of the Global Competencies Inventory for Determining Global Leadership Outcomes" (2016). Master's Theses. 4693.

DOI: https://doi.org/10.31979/etd.h37g-7pvm

https://scholarworks.sjsu.edu/etd_theses/4693

This Thesis is brought to you for free and open access by the Master's Theses and Graduate Research at SJSU ScholarWorks. It has been accepted for inclusion in Master's Theses by an authorized administrator of SJSU ScholarWorks. For more information, please contact scholarworks@sjsu.edu. 
EVALUATING THE PREDICTIVE VALIDITY OF THE GLOBAL COMPETENCIES INVENTORY FOR DETERMINING GLOBAL LEADERSHIP OUTCOMES

\author{
A Thesis \\ Presented to \\ The Faculty of the Department of Psychology \\ San José State University \\ In Partial Fulfillment \\ of the Requirements for the Degree \\ Master of Science
}

by

Emily T. Le

May 2016 
(C) 2016

Emily T. Le

ALL RIGHTS RESERVED 
The Designated Thesis Committee Approves the Thesis Titled

EVALUATING THE PREDICTIVE VALIDITY OF THE GLOBAL COMPETENCIES INVENTORY FOR DETERMINING GLOBAL LEADERSHIP OUTCOMES

by

Emily T. Le

APPROVED FOR THE DEPARTMENT OF PSYCHOLOGY

SAN JOSÉ STATE UNIVERSITY

May 2016

$\begin{array}{ll}\text { Dr. Altovise Rogers } & \text { Department of Psychology } \\ \text { Dr. Joyce Osland } & \text { School of Global Innovation and Leadership } \\ \text { Tim Brown } & \text { Radford, Aon-Hewitt and School of Management }\end{array}$ 


\section{ABSTRACT \\ EVALUATING THE PREDICTIVE VALIDITY OF THE GLOBAL COMPETENCIES INVENTORY FOR DETERMINING GLOBAL LEADERSHIP OUTCOMES}

by Emily T. Le

Due to trends in globalization, there has been an accelerated growth in the number of global organizations. This has caused the demand for global leaders to far exceed the number of qualified individuals, leading organizations to search for ways to identify individuals who will be successful global leaders. The purpose of this study was to evaluate the predictive value of one of the few validated tools for measuring global leadership, the Global Competencies Inventory (GCI). The sample consisted of 433 undergraduate and graduate students at a large public university, who were measured across three major global leadership dimensions. Correlations were analyzed for relationships between predictor variables and performance and behavioral outcomes. In order to test for moderation, linear and multiple hierarchical regression analyses were conducted. Self-management and relationship-management scores affected overall evaluations received by peers. Social desirability was negatively correlated with the overall score given by peers. Individuals with intercultural exposure though work experience scored higher in relationship-management, perception-management and overall global leadership competencies. The results of this study suggest that having a strong sense of self and good relationship skills, along with less of a desire to be viewed favorably by others, help individuals actively participate and contribute to situations that demand global leadership skills. 


\section{ACKNOWLEDGMENTS}

Any gratitude expressed on this page to my thesis committee would not truly do them justice. Dr. Altovise Rogers, Dr. Joyce Osland, and Tim Brown have been the best thesis committee a graduate student could ask for. Besides being an amazing thesis committee, these professors all truly embody the spirit of academia with their endless support and commitment to their students. My thesis committee was instrumental in my completion of my thesis in a narrow time frame. Dr. Rogers, thank you for your support throughout my tenure as a graduate student at SJSU, you are an amazing person. I also especially want to thank Dr. Osland for allowing me to use data from her studies that she tirelessly carries out every semester in order to advance the field of global leadership, as well as always being there to provide encouragement, even when I was frustrated. Tim Brown is one of the hardest working people I know, but still always goes out of his way to help his students.

I also want to thank Dr. Howard Tokunaga and Dr. Megumi Hosoda for being great, supportive professors and mentors during my time at SJSU, as well as my classmates for making so many special memories that I will carry with me forever. Also, thank you Dad and my sister Ellen Le for having faith in me. 


\section{TABLE OF CONTENTS}

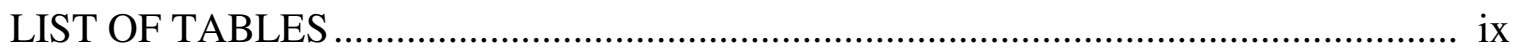

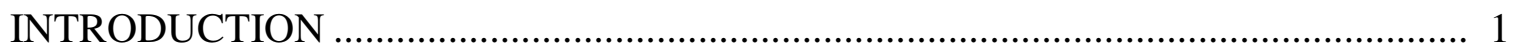

Early Research on Global Competencies.......................................................... 4

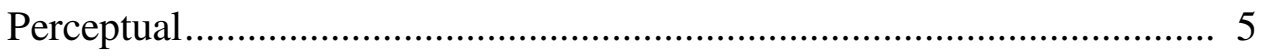

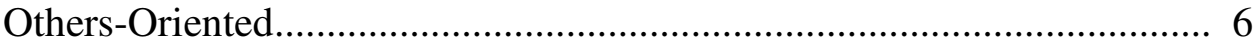

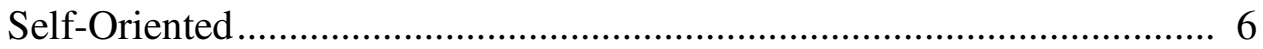

The Present State of Global Competencies ............................................................ 7

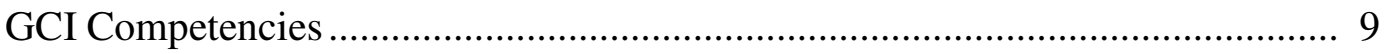

The Self-Management Dimension ............................................................ 9

The Relationship-Management Dimension .............................................. 12

The Perception-Management Dimension ................................................... 15

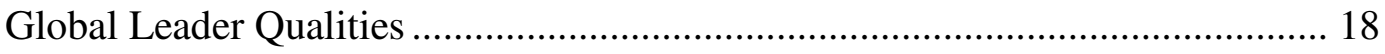

Practices of Global Leaders ....................................................................... 19

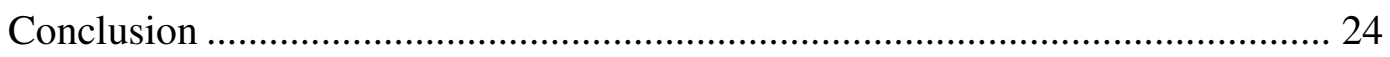

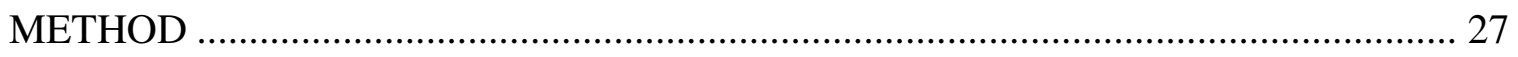

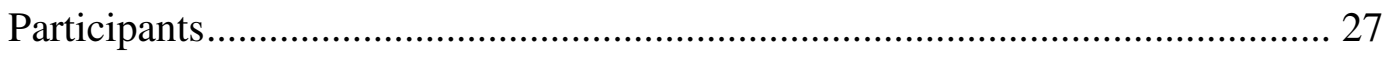

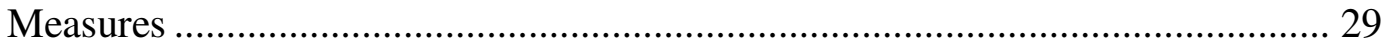

Global Leadership Competency............................................................... 29

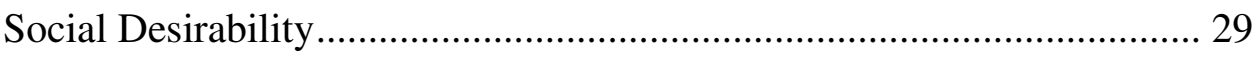

Global Leadership Performance ……………………………………....... 30

Overarching Global Leadership Behaviors............................................... 32 


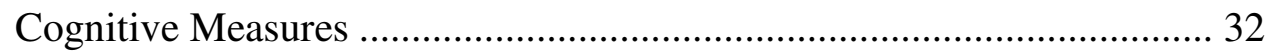

Demographic Information..................................................................... 33

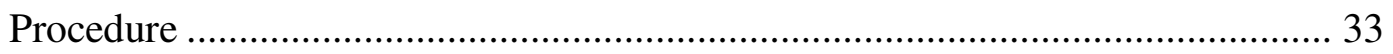

Overall Global Leadership Competency................................................... 33

Global Leadership Performance ……………………….......................... 33

Overarching Global Leadership Behaviors....................................................35

Software and Statistical Procedures......................................................... 36

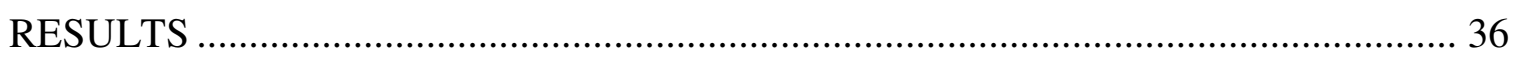

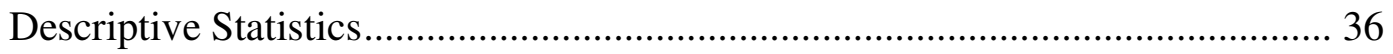

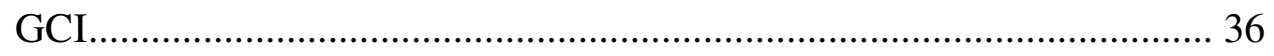

Demographic Variables .................................................................... 37

Performance and Behavioral Measures .................................................. 38

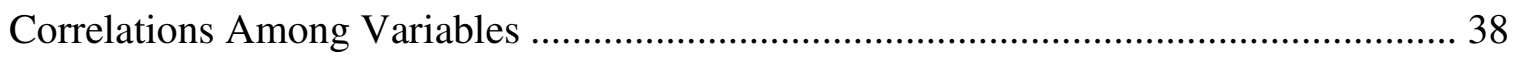

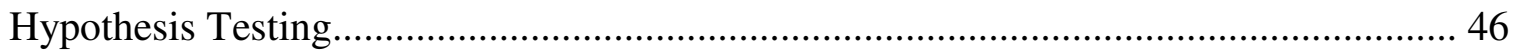

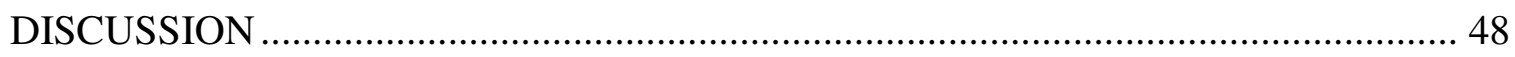

Theoretical Implications …………………………...................................... 50

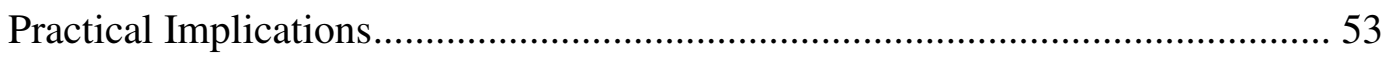

Strengths, Limitations, and Future Research ...................................................... 55

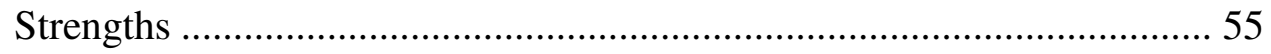

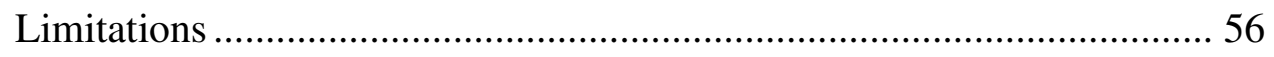

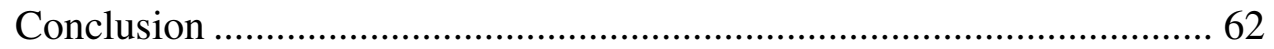

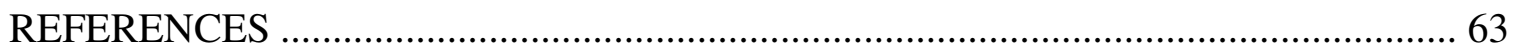




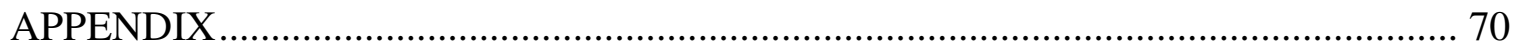




\section{LIST OF TABLES}

Table 1. Descriptive Statistics of the Participants ....................................................... 28

Table 2. Correlations Among Demographic Variables and GCI ................................ 40

Table 3. Correlations Among Global Leadership Behaviors and GCI .......................... 42

Table 4. Correlations Among Self-Evaluations and GCI ....................................... 43

Table 5. Correlations Among Peer Evaluations of Performance and GCI ...................... 45

Table 6. Results of Hierarchical Regression Analysis Predicting Stress Management .... 47

Table 7. Results of Hierarchical Multiple Regression Analysis Predicting Stress Management..... 


\section{Introduction}

Due to changes in society such as increased immigration, outsourcing, and advances in technology, organizations are becoming more global and multicultural than ever. Globalization has become increasingly necessary for organizations to maintain a competitive advantage in the volatile global economy (Osland, 2013). Even for companies that have not yet physically expanded their operations overseas and into global markets, an advanced level of global knowledge is needed in order to lead global teams and stay competitive (Osland, 2013). This is due to the fact that today employees are likely to vary in culture, religion, political beliefs, and other factors. Compared to teams in general, global teams usually have much more diverse membership (Schneider \& Barsoux, 2003). Global teams result from the increasingly intercultural workforce (Mendenhall \& Osland, 2012). There is abundant evidence that diverse workplaces can bring about positive change for organizations (Forbes, 2011; Mendenhall et al., 2013, p.150). Diversity leads to increased creativity and thus more innovation; for example, a group of diverse problem solvers can outperform a group of homogenous, high-ability performers (Albrecht \& Hall, 1991; Hong \& Page, 2004, Walter, 2014). Technology has also made it easier for organizations to create culturally diverse teams through the introduction of global, virtual teams (Kayworth \& Leidner, 2002).

The move towards more heterogeneous organizations has led to a need for global leaders to manage these diversified workplaces. The World Economic Forum's 2013 “Global Agenda Outlook" listed the ten most urgent global issues to be addressed, based on the discussions of over 1500 global experts from around the world (WEF, 2013). The 
"global leadership vacuum" was a top concern for 2013 and beyond (Osland, Li, \& Wang, 2014; WEF, 2013). The lack of global leaders presents a critical obstacle that companies must find some way to overcome to become successful internationally. A survey of business leaders from around the world in the McKinsey Quarterly (2012) identified global leadership as the factor most identified as the key factor to achieving global success. As a result of global expansion efforts, significant numbers of employees are given international assignments by their employers, making it more important for companies to individuals with global leadership potential. Contrary to popular belief, global leadership knowledge does not result only from experience, but can be developed through training (Ghemawat, 2012; Tien-Chen \& McLean, 2011). A scale that can measure global leadership competencies and predict global leadership performance is necessary to identify those who would benefit from intercultural training. One of the most promising tools for measuring global competencies is the Global Competencies Inventory (GCI) by the Kozai Group (Mendenhall, Stevens, Bird, \& Oddou, 2010).

Even though the term global leadership first emerged in the 1990s, as late as 2011, searches conducted of the field revealed only about 20 empirical studies (Mendenhall \& Osland, 2012). However, in the 2012 to 2013 period alone, at least 16 empirical articles and 10 conceptual articles on global leadership were published (Mendenhall \& Osland, 2012). These included articles in respected journals such as the Journal of World Business and the European Journal of International Management (Maznevski, Stahl, \& Mendenhall, 2013; Steers, Sanchez-Runde, \& Nardon, 2012). Despite interest in global leadership literature and the need for global leaders in 
organizations being at a record high, there is still a lack of qualified global leaders (Osland, Li, \& Wang, 2014; WEF, 2013) The key to overcoming the dearth of global leadership research and global leaders lies in acquiring more knowledge about what competencies make up a "global" leader versus a domestic leader. The purpose of this research is to examine the predictive validity of the GCI. As the field of global leadership is still emerging, there is not yet an availability of validated tools for measuring global leadership competencies. Finding a valid and reliable tool to measure global competencies is necessary to identify those best suited for global assignments or for work in diverse organizations.

In the next section, I will cover the research behind what the GCI aims to cover conceptually. The earliest research defining global leadership and its dimensions will be examined, in order to give a better conceptual overview of the GCI and the competencies that the scale intends to measure. Then I will discuss the different performance criteria that are related to the global leadership competencies that should be predicted by the GCI. These performance criteria include behaviors that are consistently associated with effective global leadership. Overall, the main purpose of this study is to provide further evidence of validity of the GCI, which was recently validated in a 2014 study (Stevens, Bird, Mendenhall, \& Oddou, 2014). To the author's best knowledge, the GCI is thus far, the only validated tool for measuring global leadership competencies. As global leadership is a multidisciplinary field, this study also aims to contribute to the overall knowledge on global leadership, management, multiculturalism, and expatriation by 
helping to clarify terms and constructs within the fields of academia related to global leadership.

\section{Early Research on Global Competencies}

Expatriates are "employees who have been sent by their employers to reside and work outside of their home country to a related unit in a foreign country on temporary assignment, usually for a term that lasts more than six months and less than five years" (Aycan \& Kanungo, 1997, p. 4). The term "expatriate" can be used to refer to "business people, diplomats, employees of international non-profit organizations, military personnel, and missionaries among others" (Osland, 2013, p. 25). For the multidisciplinary field of global leadership, studies of expatriation have emerged as a critical source of knowledge for companies seeking information on how to best prepare their employees. Expatriate adjustment literature has also helped to form the basis of global competencies research. At a basic level, global competencies have been described as the ability to function effectively in a culture different from one's own (Dinges \& Baldwin, 1996; Gertsen, 1990). In the context of management, it is crucial to identify the managers who will be most successful in a global context if sent overseas. Bird and Osland (2004) explained in their rationale for studying global competencies that while many leaders work in a global context, not all of them are global leaders. Therefore, Bird and Osland (2004) define global competencies as "the various traits, attitudes, skills, and abilities that comprise global managerial expertise" (Bird \& Osland, 2004, p. 58). Deardorff (2004) noted that there is widespread disparity in defining the domains that specifically comprise intercultural/global competence. Chen and Starosta (1996) pointed 
out that such cross-cultural competencies are often described as involving affective, cognitive and behavioral aspects. Leiba-O'Sullivan (1999) further distinguished stable and dynamic competencies, noting that the former are stable and enduring, while the latter are developed from training or life experience. Dynamic competencies are also highly context and task-dependent.

The theoretical foundation for the GCI scale and global leadership competencies was started with research by Mendenhall and Oddou (1985) when they reviewed the literature that evaluated variables that influenced successful expatriate acculturation. As global leadership was not established as its own unique field of research until the early 1990s, this study paved the way for future global leadership scholarship (Osland, 2013, p. 41). Mendenhall and Oddou (1985) were able to identify three major categories of competencies. The three main factors identified were perceptual, others-oriented, and self-oriented. They will be described in the following sections.

Perceptual. This category identified by Mendenhall and Oddou (1985), is comprised of competencies that are mainly cognitive in nature. Such competencies have to do with one's ability to "understand why foreigners behave the way they do...to make correct attributions about the reasons or causes of host-nationals' behavior...thus reducing uncertainty in interpersonal and intercultural relations" (Mendenhall \& Oddou, 1985, p. 22). A follow-up study supported that the perceptual dimension contains competencies that assist global leaders in making accurate attributions regarding the implicit intentions behind observed behavior by people of different cultures. This ability to more accurately "read" individuals from other cultures allows those high in perceptual 
competencies to then form nonjudgmental evaluations of cross-cultural encounters, which prevent biases from affecting intercultural interactions (Mendenhall et al., 2008). High perceptual abilities can assist global leaders in adjusting their cognitive schema in accurate and productive ways that lead to selection of effective social and leadership behaviors (Mendenhall et al., 2008). Empirical support for self-awareness as a factor that leads to successful relationships is extensive (e.g. study for an example), which is important because successful relationship-building is essential for leadership (Chuang, 2013). Effective leaders must be able to use their relationship skills to win the trust and support of followers (Dimitrov, Dawson, Olsen, \& Meadows, 2014).

Others-Oriented. Competencies within the others-oriented category are those crucial to working with, managing, and leading culturally different coworkers and subordinates. As mentioned earlier, interacting effectively at the interpersonal level has been found to be strongly related to both global leaders and expatriates' abilities to work effectively in a global context (Mendenhall \& Osland, 2002). Significant empirical evidence has found that the expatriate's ability to develop long-lasting friendships with host-nationals is an important factor in successful overseas adjustment, "accounting for large portions of variance in factor analytic studies studying adjustment" (Mendenhall \& Oddou, 1985, p. 41).

Self-Oriented. The third category of competencies identified in the literature review by Mendenhall and Oddou (1985) consists of "activities and attributes that serve to strengthen the expatriate's self-esteem, self-confidence, and mental hygiene" (Mendenhall \& Oddou, 1985). Some examples of the competencies in this dimension are 
one's ability to cope with stress, psychological hardiness, self-confidence, and optimism (Mendenhall et al., 2008). Being high in the competencies in this category helps expatriates to cope with the loneliness and trauma that can come with being immersed in a new culture. For example, Mendenhall and Oddou (1985) described a process they termed interest flexibility, where expatriates are able to replace activities that brought them pleasure in their home countries with similar, but different activities that exist in the host country. For example, this could involve an American expatriate who is a fan of American football and eating steak, learning to appreciate soccer and eating raw seafood in a host country where American pastimes are not as readily available.

\section{The Present State of Global Competencies}

In The Dimensions of Expatriate Acculturation: A Review, by Mendenhall and Oddou (1985), they identified three categories called the perceptual, others, and self that are associated with expatriation success. Their study is an important theoretical contribution. Konopaske, Mendenhall, and Thomason (2009) found the 1985 literature review to be the second most cited article on expatriation within the field of international management. However, based on the theoretical framework laid out by Mendenhall and Oddou (1985), the three categories of competencies have evolved into a more comprehensive framework called the International Adjustment (IA) model (Black, Mendenhall, and Oddou, 1991). The IA model was created by integrating the "theoretical and empirical work of both the international and domestic adjustment literatures" in order to create a more comprehensive model of what leads to successful cultural adjustment (Black et al., 1991). The IA model has become influential in the field of global leadership 
literature and research, with Bhaskar-Shivinas et al. (2005), p. 257, stating it was "the most influential and often-cited theoretical treatment of expatriate experience."

With the IA model, the three categories from the literature review by Mendenhall and Oddou (1985) were expanded on by Black et al. (1991), eventually evolving into the self-management, relationship-management, and perception-management dimensions that the GCI attempts to measure. The self-oriented dimension formed the basis for selfmanagement, and differed in that there was an added emphasis on Bandura's (1977) conceptualization, where individual's beliefs about their ability to succeed in new tasks influences future outcomes similar to a self-fulfilling prophecy. The others-oriented dimension evolved into the more detailed relationship-management dimension, with more of an emphasis on the individual's orientation toward the importance of relationships in general, while the perceptual dimension formed the theoretical foundation for the perception-management dimension, and was made more comprehensive conceptually (Bird et al., 2010). These constructs together form the individual component of the IA model, with other determinants of expatriate adjustment including factors beyond the individual such as one's job, organization, and non-work determinants (Black et al., 1991). The IA model construct differences will be discussed more in the next section.

The dimensions of the GCI constructed and administered by the Kozai Group are formulated around the constructs that make up the individual dimension of the IA model of expatriation adjustment. The GCI is a "160-item self-report measure that assesses the degree to which individuals possess the intercultural competencies that are associated with global leader effectiveness" (Stevens et al., 2014, p. 115). It consists of three main 
constructs, based on the individual component of the IA model, with each of the three constructs having additional sub-dimensions within it. In order to provide support for the GCI as a sound scale for measuring global leadership competencies that was created using reliable academic research, I will discuss the content domain of the dimensions and sub-dimensions within the GCI, as they relate to the global leadership literature. As the field of global leadership assessment is still emerging, the goal of this study is to help fill the gap in knowledge when it comes to validated global leadership assessment tools (Bird \& Stevens, 2013, p. 113). There are a handful of other global leadership assessment tools such as the Global Mindset Inventory (GMI), by the Thunderbird School of Global Management's Global Mindset Institute (Bird \& Stevens, 2013, p. 128), or the Global Executive Leadership Inventory (GELI) by Manfred Kets de Vries and his associates (Bird \& Stevens, 2013, p. 134). However, this study's focus will be the GCI.

\section{GCI Competencies}

The self-management dimension. In the GCI, questions relating to the selfefficacy dimension of the IA model comprise a factor called self-management. This factor involves two aspects of managing the self: strength of identity and the ability to effectively manage emotions and stress (Bird et al., 2010; Mendenhall et al., 2008). Within the three main constructs of the GCI, there are sub-dimensions. Six discrete dimensions comprise the self-management factor: optimism, self-confidence, self-identity, emotional resilience, non-stress tendency, and stress management. I will discuss these sub-dimensions in more detail. 
Optimism is defined as the "extent to which a person maintains a positive, buoyant outlook toward other people, events, situations, and outcomes" (Mendenhall et al. 2008, p. 14). The inclusion of optimism as a dimension under self-management is based on research in global leadership and expatriate disciplines (Caliguri, 2004; Gertson, 1990; Kealey, 1996; Kuhlman \& Stahl, 1996; McCall \& Hollenbeck, 2002; Ones \& Viswesvaran, 1997). Another study found that one of the best predictors of professional effectiveness overseas is a positive attitude on the part of the expatriate; "feelings of being positive, excited, strong, and determined ... are indicators of potential to succeed" (Kealey, 1996, p. 86). Self-confidence, also frequently referred to as self-efficacy in global leadership research, refers to the trust and confidence people have in themselves to succeed, and the inclination to believe that through persistence they can overcome obstacles in the path to their goals (Stevens et al., 2014). There has been support for selfconfidence as an important contributor to intercultural effectiveness and expatriate adjustment, along with being reported as a significant predictor to success on overseas assignments (Bhaskar-Shrivinas et al., 2005). Self-identity refers to the degree to which people are able to maintain strong personal values, independent of situational factors and have a strong sense of personal identity (Bird et al., 2010, p. 819; Mendenhall et al., 2008, Stevens et al., 2014). People who have high self-identity "can adapt culturally, but will do it in a way that maintains a strong framework of personal values" (Mendenhall et al., 2008, p. 16). Thus, someone high in self-identity makes accommodations to adapt to their new culture but will still find a way to hang on to their morals and personal values. 
Emotional resilience is the degree to which a person possesses the emotional hardiness and resilience to cope with stressful, ambiguous, and difficult intercultural situations (Bird et al., 2010, Mendenhall et al., 2008, Stevens et al., 2014). Non-stress tendency is "the scope of the dysfunctional stressors that may influence people in their daily work and social life in intercultural interactions" (Mendenhall et al., 2008, p. 17). It is the ability to remain calm despite challenges or difficult situations. Kealey (1996) described learning to be patient as critical for success. People with higher non-stress tendencies are more resilient to stress in the context of global leadership and intercultural interaction (Kets de Vries, Vrignaud \& Florent-Treacy, 2004). Kets de Vries et al. (2004) also referred to this trait as "resilience to stress." It concerns an individual's internal predisposition to view particular contexts or events as stressful, regardless of how many stressors are actually present. Stress management concerns the extent to which individuals are able to use various techniques or activities to cope with and recover from stress, while also effectively organizing their time. Individuals who actively engage in stress management practices while effectively managing time have increased emotional resilience, which then increases the individual's ability to deploy other global competencies effectively (Stevens et al., 2014).

Together, the six dimensions of optimism, self-confidence, self-identity, emotional resilience, non-stress tendency, and stress management form the selfmanagement component of the GCI, which should be used collectively with the other two factors of the GCI, relationship-management and perception-management, to predict global competencies and global leadership. The dimensions were formed out of empirical 
research, but have not been individually validated in terms of predicting different performance outcomes. In the next section, I will discuss the relationship-management dimension.

The relationship-management dimension. Relationship-management is a person's emphasis on the importance of relationships in general. Some examples of a person's attitudes towards the importance of relationships might be their interest in and awareness of others, interaction styles and values, and self-awareness. In a global context, it is very important for leaders to develop strong relationships with others in order to meet the needs of culturally diverse employees (Bird et al., 2010; Mendenhall et al., 2008). Even for those not in a leadership position, intercultural relationship-management has been found to be necessary for effective intercultural job performance (Harrison \& Shaffer, 2005; Mol et al., 2005). There are five discrete dimensions that make up the relationship-management factor on the GCI: relationship interest, interpersonal engagement, emotional sensitivity, self-awareness, and social flexibility.

The first sub-dimension, relationship interest, is the degree to which people possess awareness of their social environment and take interest in it (Mendenhall et al., 2008). This dimension is seen in both intercultural and domestic adjustment literature. Often, this dimension is included with other similar dimensions under a broader construct that represents interpersonal competence (Bird et al., 2010; Mendenhall et al., 2008). For example, Mol and associates (2005) labeled the relationship interest concept as interpersonal interest and found it to be a reliable predictor of expatriate job performance. This means that those who are higher in relationship interest perform better on overseas 
assignments compared to their peers who have a lower interest in and awareness of their social environment. Another sub-dimension, interpersonal engagement is defined as the extent to which individuals have a desire and willingness to initiate and maintain relationships with individuals from other cultures (Mendenhall et al., 2008). It is more specific to the interest in relationships with individuals of another culture, rather than one's general interest in his or her social environment. While the literature on this dimension is often disjointed with it being assigned various labels by different researchers, it is widely agreed that relationship development is a strong predictor of intercultural effectiveness (Bird et al., 2010). Even with some of the confusion in the literature regarding what to name this dimension, a meta-analysis of expatriate adjustment found that the variance explained by relationship-management skills "exceeded that explained by other predictors by 30 percent" when it came to predicting success overseas (Bhaskar-Shrinivas et al., 2005, p. 272).

Emotional sensitivity concerns the extent to which people are aware of and have sensitivity towards the emotions of others (Mendenhall et al., 2008). This dimension is very similar to the agreeableness dimension in the five factor model of personality (Stevens et al., 2014, p. 123; Mol et al. 2005). Numerous studies have found that people higher in empathy are more likely to form stronger relationships and win over followers, which is important for effective leadership. The dimension of agreeableness was found to be a predictor of expatriate job performance and social interaction adjustment in previous studies (Mol et al., 2005, Shaffer et al., 2006). There is also significant research supporting the importance of emotional sensitivity to intercultural effectiveness (Cui \& 
Van den Berg, 1991; Jordan \& Cartwright, 1998; Martin \& Hammer, 1989; Selmer, 2001). Another sub-dimension of relationship-management on the GCI, self-awareness, is the degree to which people possess awareness of themselves when interacting with others (Stevens et al., 2014). People high in self-awareness are aware of personal strengths and weaknesses in interpersonal skills, use past experiences to help form their self-concept, and are aware of how one's beliefs and actions might impact those who are culturally different (Bird et al., 2010, Mendenhall et al., 2008). Therefore, they are more aware of how to present themselves in a culturally appropriate manner. The final sub-dimension, social flexibility, is the extent to which individuals make an effort to present themselves in a favorable manner to others in order to create good impressions and facilitate the building of relationships (Mendenhall et al., 2008). Other researchers have called this dimension "self-monitoring" as it involves individuals being able to modify their ideas and behavior, make compromises, and be more welcoming to new ways of accomplishing things (Snyder, 1974). This dimension was included in the GCI because social flexibility has been associated with successful expatriate adjustment and effective functioning in intercultural settings (Caliguri, 1995; Hechanova et al., 2003, Mendenhall \& Osland, 2002; Montagliani, 1996).

To summarize, the relationship-management dimension of the GCI consists of the sub-dimensions of relationship interest, interpersonal engagement, emotional sensitivity, self-awareness, and social flexibility. These dimensions have been justified by the research literature on global leadership and expatriate adjustment. If these dimensions have been accurately defined by the GCI, those who score high in this dimension on the 
GCI should also perform well in social situations that would utilize such skills as selfawareness or interpersonal engagement, which will be examined later by studies involving simulations designed to mimic realistic intercultural situations.

The perception-management dimension. Perception-management on the GCI is the cognitive approach that people utilize to form perceptions of the world around them, particularly when it comes to cultural differences. This construct involves using "mental flexibility when confronted with cultural differences, the tendency to avoid making quick judgments about differences, the ability to manage perceptions when confronted with situations that differ from what was expected, and the flexibility in pursuing personal interests and activities" (Mendenhall et al., 2008, p. 5). Individual perceptions play such an important role in intercultural effectiveness because they have the power to determine the conclusions individuals arrive at about a particular culture. These conclusions in turn determine the quantity, quality, and accuracy of the information individuals then use to form judgments about a specific culture and its people (Mendenhall et al., 2008). This factor consists of five discrete sub-dimensions: nonjudgmentalness, inquisitiveness, tolerance of ambiguity, cosmopolitanism, and interest flexibility.

Nonjudgmentalness is the extent to which one is inclined to avoid making quick judgments or withhold evaluative judgmental conclusions about people or situations that are new or unexpected (Mendenhall et al. 2008, Stevens et al., 2014). Another subdimension, inquisitiveness, refers to an individual's openness towards, and active pursuit of understanding ideas, values, norms, situations, and behaviors that are new and unfamiliar. This dimension encompasses a desire to seek an understanding of the 
underlying reasons for cultural differences, while avoiding a tendency to stereotype, and having a predisposition to seek opportunities for growth and learning (Bird \& Osland, 2004; Jokinen, 2005; Mendenhall et al., 2008). According to Black, Morrison, and Gregersen (1999), inquisitiveness was the most critical of the global leadership dimensions identified. It performs as conceptual "glue" by bonding other global leadership concepts together, adding more cohesiveness to the complex set of global leadership competencies.

Tolerance of ambiguity refers to an ability to cope with uncertainty in unfamiliar and complex situations. This dimension is included in the GCI because even if someone is open to new ideas or experiences, they may not be able to cope with the associated ambiguity and uncertainty (Bird et al., 2010). Reviews of global leadership literature have found tolerance of ambiguity to be an important contributor to intercultural effectiveness (Jokinen, 2005; Mendenhall \& Osland, 2002; Osland, 2013). It was also found that the ability to embrace uncertainty and be motivated by it is an important global leadership competency (Black et al., 1999). Tolerance of ambiguity also contributes to effective intercultural communication (Ruben \& Kealey, 1979). The sub-dimension cosmopolitanism is one's interest in different countries and cultures, as well as an interest in world events. Being able to view people and events beyond the borders of one's own cultural and geographic perspective has been shown to be critical to intercultural effectiveness (Goldberg, 1976, Kedia \& Mukherji, 1999). Also, being high in cosmopolitanism is particularly important for managers to operate effectively on international assignments (Bird \& Osland, 2004; Mendenhall \& Osland, 2002; Osland et 
al., 2006). The GCI by Kozai adapts Levy et al.'s (2007) framing of the cosmopolitanism dimension where it "represents a state of mind manifested as an orientation toward the outside, the other... a willingness to explore and learn from alternative systems of meaning held by others." Interest flexibility is one's willingness to exchange important personal interests from one's own background and culture with similar, but different interests from another culture (Levy et al., 2007, p. 240). Mendenhall et al. (2008) found in their literature review that discovering new interests and activities to replace old ones that do not fit within a different cultural context demonstrates flexibility and a willingness to adapt that leads to successful global leadership (Hudson \& Inkson, 2006; Zimmerman, Holman, \& Sparrow, 2003).

The five sub-dimensions described in this section of nonjudgmentalness, inquisitiveness, tolerance of ambiguity, cosmopolitanism, and interest flexibility make up the perception management dimension on the GCI and should ideally help predict how one performs in a global context. In the methods section of this paper, I will discuss the simulations that were designed to utilize one's cross-cultural skills. All of the simulations involve some form of intercultural negotiation, where people from different cultures negotiate to reach an agreement on various organizational, economic, or business issues. All three main factors of the GCI, should be able to predict individual performance in intercultural negotiations. If the GCI has captured these sub-dimensions accurately, then those scoring higher in these dimensions will also be seen as more effective global leaders by their associates. 


\section{Global Leader Qualities}

The previous section discussed the conceptual basis behind the GCI and its dimensions. In this next section, the traits behind what makes a good "global" leader will be discussed. The traits that make a strong global leader are not identical with what makes a good domestic leader as not all effective domestic leaders would also be effective global leaders. To start with, the very definition of global leadership is different from leadership. Mendenhall, Reiche, Bird, and Osland (2012) reviewed the literature to see what makes the definition of leadership different when the word "global" is attached. In their review of the literature, Mendenhall et al. (2012) argued that global has three dimensions: contextual, relational, and spatial-temporal, which will be discussed in more detail. Mendenhall et al. (2012) also gave a definition of global leadership to help guide future research. A global leader was defined as "an individual who inspires a group of people to willingly pursue a positive vision in an effectively organized fashion while fostering individual and collective growth in a context characterized by significant levels of complexity, flow, and presence" (Mendenhall et al., 2012). These authors later stipulated that the "group of people" in this definition of global leader must come from multiple cultures (Reiche, Bird, Mendenhall, \& Osland, 2015).

The contextual dimension in the global construct of global leadership refers to the level of complexity that is an innate part of an international leader's responsibilities. This complexity determines whether one can truly be deemed a global leader. The relationship dimension of global refers to flow, or the boundary spanning aspect of a global leader's work. The degree of flow can be determined by measuring the intensity (frequency, 
volume, and scope of information flow) along with the quantity (number of channels required to perform the requisite boundary spanning in the role) of the individual's duties. This third dimension of being global, as it refers to global leadership, the spatial-temporal dimension was also termed presence by Mendenhall et al. (2012). This third dimension leading globally, is the degree to which an individual has to physically travel across geographical, cultural, and national boundaries rather than communicating across such boundaries by using virtual technologies. These dimensions should be used to "select samples and to distinguish among global managers, domestic leaders, and global leaders" (Osland, 2013, p. 75). According to the above research, it appears that it is virtually a requirement of the global leader to be able to demonstrate higher cognitive processing ability and complex critical thinking when working across cultural or geographic boundaries.

\section{Practices of Global Leaders}

With this understanding of what it means to be a global leader, as opposed to a domestic leader, it is also important to examine what a global leader in action would look like. There are numerous well-known, real-life examples of people who could be considered global leaders. Osland and Bird (2013) cite Carlos Ghosn, the CEO and Chairman of French-based company Renault, the CEO of Japan-based Nissan, and Chairman of Russian-based AvtoVAZ, as an example of a successful global leader. While leading companies in different countries, he was able to return Renault to profitability in the late 1990s, while also saving Nissan from near bankruptcy in 1999. Nissan's leadership in the electric car market along with its multinational alliance with 
Renault are attributed to Ghosn's effective global leadership. Starting in the early 1990s, an increasing number of scholars have attempted to study global leaders in order to delineate the traits, behaviors, and skills that are critical to their success. As mentioned earlier in the discussion of the research behind the domains of the GCI, reviews of the literature on global leadership have found that social scientists have delineated over 160 competencies that influence global leadership effectiveness; however, many of these competencies overlap conceptually and often only differ semantically (Bird, 2013, Jokinen 2005). This is why in order to validate the GCI, a tool aimed at Global Leadership competencies, one should know how an effective global leader would act in situations that call for global leadership. The next section will cover behaviors and skills of effective global leaders and how they should be predicted by the GCI, if the GCI does indeed measure what it set out to conceptually capture.

There are certain skills and competencies one would expect to consistently observe when watching a successful global leader in action. These observable and measurable behaviors and skills will be the criterion variables in the validity study of the GCI. As discussed earlier, one of the three main constructs of the GCI is called the relationship-management dimension. Forming connections while also maintaining new friendships is key for individuals to successfully work across cultures. As such, if one were to observe those who scored high in the relationship-management dimension of the GCI working with those of another culture, there are several key relationship-building behaviors that would be expected if this GCI construct is indeed a valid measure. 
Active listening skills such as carefully listening to what the other party/parties have to say, paraphrasing, reflecting on underlying implications and feelings, along with asking appropriate questions in order to clarify any potential misunderstanding are skills that should be predicted by the GCI (Graham, 1983; Mumford, Campion, \& Morgeson, 2007).

Connecting and finding common ground involves an individual respecting the wishes of the other person/party involved in a negotiation while making efforts to come to solutions that satisfy both parties (Mumford, Zaccaro, Connelly, \& Marks, 2000). Being able to appropriately adapt communication style and behavior, along with codeswitching are skills that should be observed in those scoring high on the GCI. Effective global leaders should be able to utilize knowledge of other cultures to effectively communicate with those from other cultures (Crossman \& Bordia, 2008; Molinski, 2007; Mukherjee \& Ramos-Salazar, 2014). For example, this could be a person from an individualistic, Western country changing their behavior to be more in line with collectivist Eastern values when trying to form a connection or reach an agreement.

It has been argued that influential, effective leaders are more likely to have high intelligence and cognitive processing ability (Keung \& Rockinson-Szapkiw, 2013; VanderPal, 2014). Compared to domestic leadership, the roles and duties associated with being a global leader are even more complex as seen by Mendenhall et al. (2012)'s delineation of the term global in global leadership. As such, one would expect to find signs of high-level cognitive ability in those scoring high in global competencies, 
particularly the perception-management dimension of the GCI. There are certain behaviors one would expect to see in an effective global leader.

Being non-judgmental is a key behavior that global leaders should demonstrate. Global leaders and expatriates are constantly exposed to unfamiliar situations, customs, ideas or practices. Rather than questioning the non-culturally familiar, a person high in global leadership qualities would be expected to demonstrate open-mindedness and not let any judgmental behavior manifest in any way (Mendenhall et al., 2008).

Along with demonstrating non-judgmental and open-minded behaviors, an individual scoring high in global competencies should be able to accurately read cues and decode the cultural behavior of others. For example, an effective global leader is expected to be able to pick up on cues and demonstrate understanding of another person's cultural behavior (Mendenhall et al., 2008). Being open to other cultures alone, will not make one an effective global leader or expatriate, but also being able to understand other cultures is critical to one's success in cross-cultural interactions (Chiang, 2015).

Another key practice of effective global leaders is being able to accept ambiguity (Huber, 2003). When living in a low-context culture such as the U.S., where people rarely have subtle nuances attached to their words or actions, it can be frustrating dealing with individuals from high-context cultures, where things are often left unsaid and one has to think at a deeper level in order to understand a situation. In general, when engaging in cross-cultural interactions, many situations are often ambiguous, requiring effective global leaders to remain unfazed when faced with obscure situations (Herman, Stevens, Bird, Mendenhall, \& Oddou, 2010). Being non-judgmental, accurately reading cues and 
decoding cultural behavior, while also accepting ambiguity are all behaviors that should be related to the GCI, particular the perception-management dimension.

Displaying a strong sense of composure, especially when handling stress is a behavior that one would expect to see in someone scoring high in global leadership (Darling \& Heller, 2011; Mendenhall et al., 2008). One's ability to remain calm and resilient in the face of stress should be predicted by one's scores on the self-management dimension of the GCI.

Effective global leaders have strong communications skills and as such are rated highly by their peers when it comes to supervisor/peer evaluations. If the items of the GCI scale have accurately captured an individual's proficiency in global competencies, then this person should demonstrate an ability to problem-solve and bridge cultural differences to obtain a positive outcome, whether it is a business, political or personal negotiation (Keung \& Rockinson-Szapkiw, 2013; Tansley \& Newell, 2007). They should do this by utilizing all of the above skills and behaviors: listening skills, connecting and finding common ground, adapting communication style appropriately and behavior, being nonjudgmental, accepting ambiguity, handling stress effectively, code-switching, and accurately reading cues and decoding the cultural behavior of others to achieve the best possible results for all involved. Part of being an effective negotiator involves compromising to achieve a favorable outcome for everyone involved (Burke \& Collins, 2005; Ivanova \& Arenas, 2014). This is because both anecdotal and empirical evidence have shown that effective global leaders tend to exhibit these behaviors, and that they are especially effective when interacting with individuals across different cultures. 
Any emerging theory of global leadership would be incomplete if demographic and life background variables were not taken into account (Caligiuri \& Tarique, 2014). Numerous studies have shown support for individual-level accelerators of global leadership development (Caligiuri \& Tarique, 2014). These accelerators are traits that help learners acquire global leadership skills and abilities at a faster rate than individuals who do not possess these accelerators or are lower in them. Such accelerators include language skills, prior cross-cultural experience, and motivation (Aryee, Chay, \& Chew, 1996; Caligiuri \& Tarique, 2014; Takeuchi, Tesluk, Yun, \& Lepak, 2005). Due to the strength of support for such demographic or background variables as accelerators of an individual's ability to develop global leadership competencies, I would expect these variables to be able to moderate or mediate the relationship between one's GCI score and his or her performance in intercultural situations.

\section{Conclusion}

With an increasing number of organizations becoming cross-cultural, it is more important than ever to have effective global leaders to lead these organizations. The growing number of global organizations, along with societal changes such as outsourcing, immigration and advancing technology, make it necessary for individuals to demonstrate strong global competencies to successfully contribute to their organizations. Unfortunately, despite the increased demand for global leadership, there is still a lack of capable individuals. In order to deal with this shortage of global leaders, tools that can predict with high-validity, individuals who would make effective global leaders are required. In addition, identifying what competencies are needed to successfully lead 
global teams can help individuals lacking in cross-cultural skills to identify their strengths and weaknesses so that they may improve. Thus, that will be this study's contribution to the literature.

Based on the above discussion of theoretical implications and empirical findings relating various relationship, perception, and self-management factors as being predictive of global leadership, it was hypothesized that if the GCI by Kozai Group has truly conceptually captured what it intended to capture, than the GCI can successfully be used to predict global leadership behaviors. This is because the global competencies that the GCI sets out to measure have been correlated with effective global leaders (Bird et al., 2004; Bird et al., 2009; Mendenhall \& Oddou, 1985). The behaviors that are expected to be correlated with an individual's GCI scores are also behaviors consistently demonstrated by successful global leaders and expatriates (Bird et al., 2009). The main purpose of this study is to examine how GCI scores predict how well individuals perform in a setting that demands effective global leadership and intercultural negotiation.

In summary, the perception-management, relationship-management, and selfmanagement factors of the GCI were created using constructs from research across multiple disciplines such as expatriation, management, and global leadership. The three main factors of the GCI are intended to capture the competencies that lead to successful leadership and intercultural negotiations. The self-management factor involves two aspects of managing the self: strength of identity and the ability to effectively manage emotions and stress (Bird et al., 2010; Mendenhall et al., 2008). Six discrete dimensions comprise the self-management factor: optimism, self-confidence, self-identity, emotional 
resilience, non-stress tendency, and stress management. Being high in self-management though having a strong sense of identity and resilience allows one to assimilate into a new culture, while not becoming depressed or overwhelmed by the stress of crosscultural interaction (Bird et al., 2010). It also helps individuals to do so in a way that does not compromise their own cultural identity or values, which is necessary to lead global teams (Mendenhall et al., 2008). Relationship-management, which is comprised of the sub-dimensions of relationship interest, interpersonal engagement, emotional sensitivity, self-awareness, and social flexibility, measures the extent to which an individual values forming and maintaining relationships with others. Having a desire to form relationships with others across cultural boundaries is crucial to successful global leadership (Bird et al., 2010; Mendenhall et al., 2008). Even for non-managerial positions, employees high in this dimension are more likely to be successful when working in a multicultural environment (Harrison \& Shaffer, 2005; Mol et al., 2005). Finally, the perceptionmanagement dimension of the GCI measures one's cognitive ability, so that individuals are able to avoid making quick and inaccurate judgments about others who are culturally different. Perception-management also involves individuals being able to easily adapt and find new interests in a different culture (Mendenhall et al., 2008). Being high in the perception-management dimension should lead to effective global leadership, by allowing individuals to quickly assimilate into a new culture's customs and values. As a result, the following hypotheses are proposed: 
Hypothesis 1: The self-management, relationship-management, and perceptionmanagement dimensions of the GCI will predict key, overarching global leadership behaviors and attitudes.

Hypothesis 2: One's overall score on the GCI and perception-management score will be related to one's cognitive ability.

Hypothesis 3: Demographic variables such as one's prior exposure to other cultures at work or through international study abroad programs will moderate the relationship between one's GCI score and performance in an intercultural setting.

Besides testing the above hypotheses, the second purpose of this study is to add to the literature on global leadership measurement scales. To the author's knowledge, studies examining and validating tools intended to measure global leadership/intercultural competencies have been limited.

\section{Method}

\section{Participants}

A total of 433 college students from a large state university in California participated in the research and were administered the GCI. However, data was not collected on all moderator and outcome variables for each class. As a result, the final sample varied depending on the variable, as shown in more detail in the following tables. Participant scores on the predictor, moderator, and outcome variables were collected while the participants were enrolled in undergraduate and graduate global leadership courses at the university. Student ages ranged from 19 to 53, with the average age being 25 years old. Participants identifying as female comprised $45.30 \%$ while those 
identifying as male comprised $54.70 \%$ of the sample. Participants identifying as U.S. nationals who had been born in the United States comprised $23.62 \%$, while $76.38 \%$ were international students, expatriates, or individuals who had moved to the United States after they were born. Individuals who identified as being nationals of another country comprised $27.80 \%$ of the sample, while $72.20 \%$ were of U.S. nationality. Demographic information for the participants is displayed in Table 1.

\section{Table 1}

Descriptive Statistics for the Participants

\begin{tabular}{|c|c|c|}
\hline Variable & $\bar{f}$ & $\%$ \\
\hline \multicolumn{3}{|l|}{ Gender $(N=353)$} \\
\hline Male & 193 & 54.67 \\
\hline Female & 160 & 45.33 \\
\hline \multicolumn{3}{|l|}{ Age (years) $(N=354)$} \\
\hline $19-22$ & 132 & 37.29 \\
\hline $23-26$ & 119 & 33.62 \\
\hline $27-30$ & 54 & 15.25 \\
\hline $31-34$ & 24 & 6.78 \\
\hline $35+$ & 25 & 7.06 \\
\hline \multicolumn{3}{|l|}{ Nationality $(N=249)$} \\
\hline North America & 180 & 72.29 \\
\hline Central America & 4 & 1.61 \\
\hline South America & 1 & .40 \\
\hline Western Europe & 18 & 7.23 \\
\hline Eastern Europe & 3 & 1.20 \\
\hline Asia & 38 & 15.26 \\
\hline Africa & 4 & 1.61 \\
\hline Pacific Island & 1 & .40 \\
\hline \multicolumn{3}{|l|}{ Ethnicity $(N=277)$} \\
\hline $\begin{array}{l}\text { Native American or } \\
\text { American Indian }\end{array}$ & 11 & 1.67 \\
\hline Asian & 112 & 40.43 \\
\hline Black & 20 & 7.22 \\
\hline $\begin{array}{l}\text { Pacific Islander or Native } \\
\text { Hawaiian }\end{array}$ & 5 & 1.81 \\
\hline White & 129 & 46.57 \\
\hline
\end{tabular}




\section{Measures}

Global leadership competency. The GCI was used to measure overall

intercultural global leadership competency (Bird et al., 2010; Mendenhall et al., 2010;

Stevens et al., 2014). It measures sixteen global leadership competencies that fall under the three main factors of perception-management, relationship-management, and selfmanagement. All 171 items were formulated as self-report statements using a Likert 5point scale format, ranging from 1="Strongly Disagree" 2="Disagree," $3=$ "Neither Agree nor Disagree,” 4=“Agree,” to 5=“Strongly Agree.” GCI participants were provided with scores on all seventeen individual dimensions as well as the three main factors of perception-management, relationship-management, and self-management.

Social Desirability. There was also a hidden social desirability index included within the $171 \mathrm{GCI}$ items, which was intended to make the scale more accurate by identifying participant dishonesty (Stevens et al., 2014). Social desirability is a tendency among survey respondents to answer in a manner that will be viewed favorably by others. It is important to take into account social desirability, as it can greatly affect the reliability of psychometric scales (Beretvas, Meyers, \& Leite, 2002; Van de Mortel, 2008). For the purpose of this study, the social desirability dimension of the GCI was treated as a control variable, in order to reduce the confounding effects of social desirability. When evaluating the participant's performance and behaviors during the simulations, it was also of interest to see if their social desirability score on the GCI could possibly influence their display of social desirability during the simulations. 
Global leadership performance. In order to measure outcome variables, such as global leadership effectiveness and its relationship with the GCI, participants were observed in a simulation designed to measure one's global leadership effectiveness in an intercultural business negotiation. In the global leadership simulation used in this study, titled "Alpha Beta" participants are members of a team and are instructed to negotiate an agreement with members from another fictitious foreign company. A factor that makes this negotiation a global leadership exercise is that the two teams are from different countries and as a result have different cultural values and social behaviors. Students were given instructions on how to represent their culture and were also instructed to obtain a certain outcome for their company.

Throughout the Alpha Beta simulations participants are required to actively decode behavior, display intercultural sensitivity and adjust their behavior to accommodate that of the foreign culture. The negotiation also assesses participant ability to tolerate ambiguity, be persuasive and effectively communicate their ideas. All simulations were recorded in a controlled classroom environment as part of research for the Global Leadership Advancement Center (GLAC) in a room designated as the Global Leadership (GL) Lab.

Some of the outcome measures that were used in the study consisted of selfevaluation and peer evaluations from other participants. For some undergraduate classes participating in a global leadership development course, undergraduate students also received feedback from graduate students observing their performance in the simulation. The team evaluation sheet that participants are given at the end of the Alpha Beta 
negotiation consisted of ratings for both one's own team and the opposing team, rated on a scale from 1 to 3 , where 1 = "Poor," 2 = "Average," and 3 = "Excellent." Participants rated themselves and each other on a total of six outcome measures: overall contribution to the negotiation, as well as five behaviors important to global leadership in real-life settings. The self-evaluation and graduate student evaluation sheets included the same behavioral measures as the team evaluation, rated on the same scale of 1-3 (see Alpha Beta negotiation evaluation sheets for in appendix). The skills that participants are evaluated on include performance measures intended to relate to the perceptionmanagement GCI dimensions such as one's ability to accurately read cues and decode cultural behavior. Such behaviors of picking up on cultural cues and code-switching are necessary for effective global leadership (Levy et al., 2007; Osland, 2013). Also, the ability to withhold judgment and cope with ambiguity is crucial due to the complexity of global leadership (Mendenhall, 2012; Osland et al., 2007). For the Alpha Beta negotiation, the rubric used to rate other participants was specific to negotiation. Participants were rated on their ability to communicate ideas effectively to the other party, arguably an important feature of a good leader. As discussed in the introduction, global leadership is similar to domestic leadership, but varies in scale and complexity (Mendenhall et al., 2012; Osland et al., 2014). Negotiation and communication abilities are commonly argued as key features of leadership in general, and remain important leadership behaviors in the global context (Yukl, 2012). To help ensure that students are staying on track, at the halfway point of the negotiation, they are given a process check form to fill out (see Process Check in the Appendix). This form serves as a cognitive 
outcome as it measures whether participants have decoded the other team's behavior and created a negotiation strategy to be more effective.

Overarching global leadership behaviors. Furthermore, the participants were rated by graduate student evaluators on overarching behaviors that are considered fundamental to global leadership (Osland et al. 2007). Participants were evaluated on eight key global leadership behaviors that consisted of active listening, connecting and finding common ground, appropriately adapting communication style and behavior, nonjudgmentalness, accurately reading cues and decoding the behaviors of those from another culture, tolerating ambiguity, handling stress, and bridging cultural differences to achieve a positive outcome. Ratings varied from 1 to 3 with 1 being the lowest, implying the participant did not display that behavior at all or engaged in the exact opposite of that behavior, such as acting judgmentally, while 3 was the highest, suggesting the participant did an excellent job of displaying the given behavior. All of these overarching global leadership behaviors have consistently been supported by studies as necessary for successful global leadership (Mendenhall et al., 2008).

Cognitive measures. The first cognitive variable evaluated consisted of participants' final grades for the course, as part of this study's goal is to assess the GCI's predictive value for cognitive ability. Since this study took place at a U.S. university, grades were on a standard American, 0 to 100 grade point scale. Due to the increased complexity of global leadership when compared with domestic leadership, cognitive ability should have a statistically significant relationship with global leadership 
competencies. In addition, cognitive ability should be related to performance in situations that call for global leadership abilities, such as the GLAC simulations.

Demographic information. At the beginning of the semester, students were given an online survey that asked them various questions about their cultural background, prior to taking the global leadership class. Some questions included ones about whether the participant's family was bicultural and how long their families had lived in the United States. Others focused on global exposure and were more work-related or school-related and asked if the participant had ever studied abroad in university, interacted with a diverse group of people at work, had been on a global virtual team, or had traveled internationally for work. These were coded on a binomial scale as either $1=$ "Yes" or $2=$ "No." When conducting the linear regression portion of the study's analyses, the demographic variables were entered in as potential moderator variables.

\section{Procedure}

Overall global leadership competency. Scores for the overall intercultural global leadership competency measure were assigned by having students complete the Global Competency Inventory online by using electronic devices, such as a computer or a tablet. After responses were collected, the scores were stored on a server from which they were later retrieved in order to be included in the analyses.

Global leadership performance. As part of the ongoing research conducted by faculty of the university's global leadership department, various simulations were designed to replicate realistic intercultural situations. These simulations are designed to relate to global leadership by requiring participants to employ effective global leadership 
practices taught throughout the course in order to succeed in the negotiations, such as being understanding of different cultures and using effective communication to bridge cultural boundaries. The Alpha Beta negotiation was conducted in a classroom setting, where participants were divided into different groups and provided with instructions. The information provided to participants included two parts: private information specific to each group and public information on the business context and objectives of the negotiation. The public information included the profile and business situations of both companies, while the private information was company-specific and included the company's strategy, history and important decision points. The participants were provided with an instruction sheet which gave them full disclosure of the structure of the exercise, timeline and expectations (see student instructions in appendix). This sheet also listed the competencies found in effective negotiations, which were subsequently measured in the peer evaluation. Most of these competencies had been taught in previous class activities and readings, so the purpose of this was to reinforce global competencies knowledge, for more accurate ratings on the competencies. To ensure that participants understood their role, they completed a comprehension test before initiating the Alpha Beta negotiation. The purpose of the comprehension test is to ensure that participants understand what the simulation is about, the team they are representing, along with their team's goals for the simulation. To practice their assigned cultural approach, they were prompted to begin enacting their assigned culture-specific roles beforehand. Furthermore, they completed a worksheet to assist them in preparing a strategy for the negotiation (see Negotiation Preparation in Appendix). 
Upon completing the preparation, the participants engaged in the first 15-minute round of the negotiation with participants from the other team. In this round, participants were instructed to complete introductions and begin working toward their goal of coming to an agreement on four key issues. At the end of Round 1, teams were then given time to complete the process checks, which were completed individually. After completing the process checks, they received a five-minute break and were allowed to reconvene to discuss the strategy within their teams for the second round. In the second and final 15minute round of the negotiation, teams were instructed to reach and confirm an agreement in writing (see Negotiation Agreement in appendix). Not all teams were successful in reaching an agreement by the end of the allotted discussion time. Self, peer, and graduate evaluations were obtained after completing the simulation by having the participants rate themselves as well as their fellow team members on their performance in the exercise. Participants were asked to evaluate to the best of their ability each member of their respective groups on their performance, in terms of the behaviors outlined above.

Overarching global leadership behaviors. With participant consent, the simulations were recorded and stored on a secure server. Expert evaluators who consisted of graduate student employees of the university global leadership department later viewed these simulations and coded each individual participant on the eight overarching global leadership behaviors from the GL Lab behaviors rubric (see GL Lab Behaviors rubric in appendix). Evaluators coding the simulations videos already had knowledge of global leadership behaviors and were given a rubric that described for each key behavior 
what constituted as a 1 to 3 rating. If needed, evaluators could re-watch the videos to get a more accurate score.

\section{Software and Statistical Procedures}

The data collected in the study was analyzed using the statistical software SPSS. Correlations were analyzed to investigate the relationship between variables and to reveal statistically significant relationships at the .05 level. Linear and multiple hierarchical regressions were conducted in order to identify moderator variables. Linear regression is conducted in order to create an equation that explains the relationship between a criterion variable, $y$, and a predictor/explanatory variable, $x$ (Freedman, 2009, p. 26). In the case of more than one predictor variable, this type of analysis is called multiple regression modeling and is "almost always more appropriate for the analysis of nonexperimental research than is ANOVA (analysis of variance)" (Keith, 2016, p. 18). Both types of regression analyses were conducted in order to test the hypotheses of how much variance the individual GCI dimensions could explain for the outcome variables, along with how much variance all the GCI dimensions as a group could explain when predicting differ global leadership performance and cognitive outcome variables.

\section{Results}

\section{Descriptive Statistics}

GCI. Correlations for the variables used in the study can be viewed in Tables 2-5. The scores for overall global leadership competencies, along with the three main constructs on the GCI, were assigned on a scale of 1 to 5 , with 1 being lowest and 5 being the highest. Within the study's sample taken from 433 participants, the scores for overall 
global leadership competency ranged from 2.24 to 4.56 , with a mean score of 3.60 and a standard deviation of .33 . For the perception-management dimension of the GCI, the scores ranged from 2.21 to 2.54 , with an average score of $3.40(\mathrm{SD}=.39)$. On the relationship-management dimension, participant scores ranged from 2.57 to 4.86 and the average score was $3.87(\mathrm{SD}=.38)$. Scores on the self-management dimension ranged from 1.88 to 4.91 , with an average score of $3.52(\mathrm{SD}=.41)$. Social desirability index scores ranged from 1.25 to $4.67(\mathrm{M}=2.73, \mathrm{SD}=.59)$.

Demographic variables. For the first demographic variable analyzed, the amount of time the participant had lived in the U.S., the average was 20.02 years $(\mathrm{SD}=4.95)$. Answers given ranged from five years to 28 years, for a total range of 23 years. The next demographic variable analyzed was whether students had studied abroad internationally while attending university. $29.71 \%$ of the 276 participants surveyed had studied abroad, while $70.29 \%$ had not studied abroad internationally. When participants were asked whether they had ever worked on global virtual teams, $14.90 \%$ responded that they currently did, or had worked on them frequently, while $16.30 \%$ had occasionally worked on them. $59.10 \%$ had never been a part of a global virtual team, while $9.80 \%$ responded "not applicable - no work experience". Another demographic survey item asked whether the participant had traveled internationally for work. $13.70 \%$ answered that they had traveled internationally for work, while $74.60 \%$ answered they had not traveled internationally for work. $11.60 \%$ answered "not applicable," because they had no work experience. 
Performance and behavioral measures. Scores on global leadership

performance from self, team, and graduate evaluators had a possible range from 1 to 3 . Scores on the self-evaluation had an average of $2.71(\mathrm{SD}=.51)$. For overall scores on the team evaluations, scores ranged from 1.85 to 3 with a mean score of 2.71 . There was minimal variance across scores on the team evaluations $(\mathrm{M}=2.71, \mathrm{SD}=.33)$. As the high averages for self and team evaluations indicate, participants tended to highly rate themselves and their peers on global leadership effectiveness. For the graduate student evaluations, there were fewer evaluations in the sample $(n=65)$ as compared to self $(n=$ $402)$ and team $(n=395)$ evaluations. The average score for graduate evaluations was 2.57 $(\mathrm{SD}=.39)$. With respect to the overarching global leadership behavior variables observed, that were coded from 1 to 3 , average scores ranged from 2.30 on "appropriately adapted behavior" $(\mathrm{SD}=.77)$ to an average of 2.78 on "active listening $(\mathrm{SD}=.51)$. "Nonjudgmentalness" had an average score of $2.66(\mathrm{SD}=.60)$, while "connecting and finding common ground" had an average score of $2.49(\mathrm{SD}=.71)$. "Accurately read and decode behavior" had an average score of $2.37(\mathrm{SD}=.70)$, while "tolerance for ambiguity" had an average score of $2.67(\mathrm{SD}=.60)$, "handled stress" had an average of $2.68(\mathrm{SD}=.53)$, and "bridged cultural differences to obtain a favorable outcome" had an average of $2.37(\mathrm{SD}=.68)$.

\section{Correlations Among Variables}

Significant and high intercorrelations were found between overall global competencies scores and the three main GCI constructs of perception-management, relationship-management, and self-management. Correlations were positive and ranged 
from .54 to .86 with $p<.01$. The social desirability index was also significantly and positively correlated with all three constructs of the GCI and the overall global leadership competency. The amount of time a participant had lived in the United States was significantly correlated with the relationship-management dimension of the $\mathrm{GCI}(r=.27$, $p=.05)$. The demographic variable of whether a participant had studied abroad in the university was significantly related with the perception-management dimension of the GCI $(r=.21, p=.00)$. Having a job that required international travel was significantly related with the relationship-management dimension of the $\mathrm{GCI}(r=.21, p=.00)$, as well as having a significant relationship with overall global leadership competency $(r=.16, p$ $=.03)$. Whether the participant had ever been part of a global virtual team at work was significantly related with perception management $(r=.15, p=.05)$, relationshipmanagement $(r=.22, p=.00)$, and overall global leadership competency $(r=.17, p=$ .02). The two variables of whether a participant had a bicultural family and interacted with a diverse work-group were uncorrelated with overall GCI score with $p=.73$ for having a bicultural family background and $p=.24$ for interactions in a diverse work environment. These two demographic questions were also unrelated to the three main constructs, for bicultural family background, $p=.47, .38$, and .58 for perceptionmanagement, relationship-management, and self-management, respectively. Thus, this excluded them from being tested as moderators since a variable cannot moderate the relationship between a dependent variable and predictor variable, if it is not significantly related to the predictor or criterion (Jaccard \& Turrisi, 2003, p.1). For more detail on the correlations between the GCI and demographic variables, please refer to Table 2 . 


\begin{tabular}{|c|c|c|c|c|c|c|c|c|c|c|c|}
\hline Variable & 1 & 2 & 3 & 4 & 5 & 6 & 7 & 8 & 9 & 10 & 11 \\
\hline $\begin{array}{l}\text { 1. Overall GCI } \\
\text { score }\end{array}$ & -- & & & & & & & & & & \\
\hline $\begin{array}{l}\text { 2. Perception- } \\
\text { management }\end{array}$ & $.83 * *$ & -- & & & & & & & & & \\
\hline $\begin{array}{l}\text { 3. Relationship- } \\
\text { management }\end{array}$ & $.86 * *$ & $.58 * *$ & -- & & & & & & & & \\
\hline $\begin{array}{l}\text { 4. Self- } \\
\text { management }\end{array}$ & $.86 * *$ & $.54 * *$ & $.62 * *$ & -- & & & & & & & \\
\hline $\begin{array}{l}\text { 5. Social } \\
\text { desirability }\end{array}$ & $.23 * *$ & $.16^{* *}$ & $.14 * *$ & $.27 * *$ & -- & & & & & & \\
\hline $\begin{array}{l}\text { 6. Bicultural } \\
\text { family }\end{array}$ & -.03 & -.06 & -.08 & .05 & -.02 & -- & & & & & \\
\hline $\begin{array}{l}\text { 7. Diverse work } \\
\text { environment }\end{array}$ & .09 & .08 & .05 & .10 & .02 & .05 & -- & & & & \\
\hline $\begin{array}{l}\text { 8. Years lived in } \\
\text { U.S. }\end{array}$ & .19 & .03 & $.27^{*}$ & .17 & -.09 & N/A & N/A & -- & & & \\
\hline $\begin{array}{l}\text { 9. Studied abroad } \\
\text { internationally in } \\
\text { university }\end{array}$ & -.06 & $-.21^{* *}$ & -.08 & .12 & .09 & $-.17^{*}$ & .02 & N/A & -- & & \\
\hline $\begin{array}{l}\text { 10. Travel } \\
\text { internationally for } \\
\text { work }\end{array}$ & $-.16^{*}$ & -.13 & $-.21 * *$ & -.09 & .04 & .12 & $.40 * *$ & N/A & -.15 & -- & \\
\hline $\begin{array}{l}\text { 11. Been on } \\
\text { global virtual } \\
\text { team }\end{array}$ & $-.17 *$ & $-.15^{*}$ & $-.22 * *$ & -.09 & -.08 & $.15^{*}$ & $.27 * *$ & N/A & -.07 & .57 & -- \\
\hline
\end{tabular}

nsions of GCI

Note. $N=339, * p<.05, * * p<.01 . \mathrm{N} / \mathrm{A}=$ could not be calculated due to one variable being constant. 
Overall global leadership competency, along with the three GCI dimensions, was not found to be significantly related to global leadership performance or the overarching global leadership behaviors with $p$ values ranging from .06 to .98 , as can be seen in more detail in Table 3. Overall the GCI score was not related to average self, team, or graduate behavior outcomes ( $p=.18, .55$, and .48 , respectively). There were not enough ratings completed by graduate students to find significance among those ratings $(n=65)$.

However, when evaluating the individual items on which Alpha-Beta participants were asked to rate themselves and their peers there were significant correlations between the GCI dimensions and global leadership performance. Self-ratings of overall contribution to the simulations were significantly related to both the self-management and relationship-management dimensions of the GCI with a correlation of .12, $p=.03$ for both dimensions. In addition, the overall contribution to the simulation's self-rating was negatively correlated with social-desirability $(r=-.14, p=.01)$. For self-ratings of the item, "demonstrates the advantages of their negotiation proposals and can thereby persuade the other party to change its stance," there was a significant correlation with the self-management dimension ( $r=.12, p=.03$ ). Self-ratings of "ability to communicate ideas so that the other party fully understands what you have in mind" were also significantly related to self-management $(r=.11, p<.05)$. Table 4 contains detail on selfevaluations. 
Table 3

Pearson Correlations Among Global Leadership Behaviors and GCI

\begin{tabular}{|c|c|c|c|c|c|c|c|c|c|c|c|c|c|}
\hline Variable & 1 & 2 & 3 & 4 & 5 & 6 & 7 & 8 & 9 & 10 & 11 & 12 & 13 \\
\hline 1. Overall GCI score & -- & & & & & & & & & & & & \\
\hline $\begin{array}{l}\text { 2. Perception- } \\
\text { management }\end{array}$ & $.83 * *$ & -- & & & & & & & & & & & \\
\hline $\begin{array}{l}\text { 3. Relationship- } \\
\text { management }\end{array}$ & $.86 * *$ & $.58 * *$ & -- & & & & & & & & & & \\
\hline 4. Self-management & $.86^{* *}$ & $.54 * *$ & $.62 * *$ & -- & & & & & & & & & \\
\hline 5. Social desirability & $.23 * *$ & $.16 * *$ & $.14 * *$ & $.27 * *$ & -- & & & & & & & & \\
\hline 6. Active listening skills & -.09 & -.06 & -.12 & -.04 & .11 & -- & & & & & & & \\
\hline $\begin{array}{l}\text { 7. Being non- } \\
\text { judgmental }\end{array}$ & -.04 & -.04 & -.04 & -.02 & .00 & $.43 * *$ & -- & & & & & & \\
\hline $\begin{array}{l}\text { 8. Connecting and } \\
\text { finding common ground }\end{array}$ & -.04 & .00 & -.08 & -.03 & .08 & $.51 * *$ & $.39 * *$ & -- & & & & & \\
\hline $\begin{array}{l}\text { 9. Accurately read cues } \\
\text { and decode other's } \\
\text { cultural behavior }\end{array}$ & .03 & .07 & -.03 & .02 & .06 & $.49 * *$ & $.33 * *$ & $.66 * *$ & -- & & & & \\
\hline $\begin{array}{l}\text { 10. Appropriately adapt } \\
\text { communication style } \\
\text { and behavior, "code- } \\
\text { switch" }\end{array}$ & -.12 & -.11 & -.13 & -.07 & .09 & $.51 * *$ & $.44 * *$ & $.72 * *$ & $.76^{* *}$ & -- & & & \\
\hline 11. Tolerate ambiguity & .03 & .00 & .06 & .02 & -.01 & $.49 * *$ & $.62 * *$ & $.34 * *$ & $.37 * *$ & $.46^{* *}$ & -- & & \\
\hline 12. Handle stress & .13 & .07 & .15 & .10 & -.05 & $.44 * *$ & $.49 * *$ & $.40 * *$ & $.36 * *$ & $.40 * *$ & $.74 * *$ & -- & \\
\hline $\begin{array}{l}\text { 13. Bridged cultural } \\
\text { differences to obtain a } \\
\text { positive outcome }\end{array}$ & -.09 & -.07 & -.13 & -.03 & .05 & $.43 * *$ & $.30 * *$ & $.67 * *$ & $.77 * *$ & $.74 * *$ & $.27 * *$ & $.33 * *$ & -- \\
\hline
\end{tabular}


Table 4

Pearson Correlations Among Self-Evaluations of Performance and GCI

\begin{tabular}{|c|c|c|c|c|c|c|c|c|c|c|c|}
\hline Variable & 1 & 2 & 3 & 4 & 5 & 6 & 7 & 8 & 9 & 10 & 11 \\
\hline 1. Overall GCI score & -- & & & & & & & & & & \\
\hline 2. Perception-management & $.83 * *$ & -- & & & & & & & & & \\
\hline 3. Relationship-management & $.86^{* *}$ & $.58 * *$ & -- & & & & & & & & \\
\hline 4. Self-management & $.86 * *$ & $.54 * *$ & $.62 * *$ & -- & & & & & & & \\
\hline 5. Social desirability & $.23 * *$ & $.16^{* *}$ & $.14 * *$ & $.27 * *$ & -- & & & & & & \\
\hline 6. Question one & .10 & .03 & $.12 *$ & $.12 *$ & $-.14 * *$ & -- & & & & & \\
\hline 7. Question two & $-.14 *$ & $-.18 *$ & -.07 & -.09 & -.01 & $.22 *$ & -- & & & & \\
\hline 8. Question three & -.08 & $-.17 * *$ & -.03 & -.01 & -.03 & $.36^{* *}$ & $.39 * *$ & -- & & & \\
\hline 9. Question four & -.05 & $-.12 *$ & .01 & -.01 & -.02 & $.27 * *$ & $.30 * *$ & $.51 * *$ & -- & & \\
\hline 10. Question five & .06 & -.07 & .10 & $.12 *$ & -.09 & $.46^{* *}$ & $.25^{* *}$ & $.45 * *$ & $.45^{* *}$ & -- & \\
\hline 11. Question six & .07 & -.04 & .10 & $.11^{*}$ & -.04 & $.46^{* *}$ & $.15 * *$ & $.48 * *$ & $.37 * *$ & $.49 * *$ & -- \\
\hline
\end{tabular}


For peer evaluations, relationship-management $(r=.12, p=.02)$ and selfmanagement $(r=.16, p=.00)$, and overall global leadership competency $(r=.11, p=$ $.05)$ were also significantly related to peer-ratings of a participant's overall contribution to the negotiation. There was also a negative correlation between peer evaluations of a participant's overall contribution to the simulation and the participant's social desirability score on the GCI $(r=-.14, p=.01)$. Peer ratings of "ability to communicate ideas so that the other party fully understands what you have in mind" were significantly related to self-management $(r=.11, p=.05)$. In addition, several of the demographic variables were significantly correlated with the performance and behavior outcomes. Whether a participant had studied abroad in a university was positively correlated with how well they handled stress $(r=.22, p=.04)$. The amount of time a participant had lived in the United States was also significantly correlated with the peer evaluation ratings of the participant's overall contribution to the Alpha Beta simulation $(r=.36, p=.02)$. When evaluating the relationship between student's final grades for the course and the GCI, there was not a significant relationship between grades and any of the dimensions or overall global leadership competency $(p=.33)$. When compared with the perceptionmanagement, the GCI dimension that mainly measures cognitive competencies, results were not significant, $p=.08$. Reference Table 5 for detail on peer-evaluations. 
Table 5

Pearson Correlations Among Peer-Evaluations of Performance and GCI

\begin{tabular}{|c|c|c|c|c|c|c|c|c|c|c|c|}
\hline Variable & 1 & 2 & 3 & 4 & 5 & 6 & 7 & 8 & 9 & 10 & 11 \\
\hline 1. Overall GCI score & -- & & & & & & & & & & \\
\hline 2. Perception-management & $.83 * *$ & -- & & & & & & & & & \\
\hline 3. Relationship-management & $.86 * *$ & $.58 * *$ & -- & & & & & & & & \\
\hline 4. Self-management & $.86^{* *}$ & $.54 * *$ & $.62 * *$ & -- & & & & & & & \\
\hline 5. Social desirability & $.23 * *$ & $.16^{* *}$ & $.14 * *$ & $.27 * *$ & -- & & & & & & \\
\hline 6. Question one & .11 & -.01 & $.12 *$ & $.16^{* *}$ & $-.14 * *$ & -- & & & & & \\
\hline 7. Question two & -.01 & -.09 & .01 & .06 & -.06 & $.49 * *$ & -- & & & & \\
\hline 8. Question three & -.03 & $-.16 * *$ & .00 & .07 & -.06 & $.43^{* *}$ & $.68 * *$ & -- & & & \\
\hline 9. Question four & -.03 & $-.14 * *$ & .02 & .04 & -.09 & $.37 * *$ & $.53 * *$ & .54 & -- & & \\
\hline 10. Question five & .00 & $-.13 *$ & .05 & .09 & -.07 & $.52 * *$ & $.60 * *$ & $.60 * *$ & $.60 * *$ & -- & \\
\hline 11. Question six & .06 & -.04 & .09 & $.11 *$ & -.08 & $.58 * *$ & $.57 * *$ & $.61 * *$ & $.52 * *$ & $.66^{* *}$ & -- \\
\hline
\end{tabular}

Note. $N=339,{ }^{*} p<.05, * * p<.01$ 


\section{Hypothesis Testing}

It was stated in Hypothesis 1 that the self-management, relationship-management, and perception-management dimensions as well as overall global leadership competency would be able to predict key, overarching global leadership behaviors and attitudes. This hypothesis was partially supported since some of the performance measures and outcomes were significantly correlated with the GCI, while others were not.

Hypothesis 2 stated that one's overall score on the GCI and for perceptionmanagement will be related to one's cognitive ability. The use of student course grades as a measure of cognitive ability did not show a significant correlation. For overall GCI score and grades $r=.06, p=.33$ and for perception-management and the GCI, $p=.10, r$ $=.08$. Thus, this hypothesis was not supported.

Hypothesis 3: Demographic variables involving one's prior level of intercultural experience will moderate the relationship between one's GCI score and performance in an intercultural setting. In order to test this hypothesis, linear and multiple hierarchical regression analyses were conducted. A student's study abroad in university status was the only demographic variable that was related to both the GCI and a performance outcome variable. Whether a student had studied abroad in an university had a significant correlation of .21 with perception-management $(p=.00)$ and had a significant correlation with how well the student handled stress in the negotiation $(r=.22, p=.04)$. In the first step of the hierarchical regression analyses, perception-management was entered, followed by the participant's university study abroad status in step two. Results of the linear regression analysis indicated that whether a student studied abroad did not 
moderate the relationship between perception-management and stress handling, as there was not a significant contribution to variance explained (adjusted $\left.R^{2}=.04, p=.16\right)$. When overall GCI score along with perception-management was included as a predictor, there was still not a significant moderation effect (adjusted $R^{2}=.03, p=.22$ ). Thus, this hypothesis was not supported. Please see Table 6 and Table 7 for the results of the hierarchical regression analyses.

Table 6

Results of Hierarchical Regression Analysis Predicting Stress Management

\begin{tabular}{lllll}
\hline Steps and Predictor Variables & $\mathrm{R}^{2}$ & $\Delta \mathrm{R}^{2}$ & $r$ & $B$ \\
\hline Step 1: & 0.04 & 0.04 & & \\
Perception Management & & & 0.12 & 0.19 \\
Step 2: & 0.07 & 0.03 & & \\
Perception Management & & & .11 & 0.2 \\
Studied Abroad in University & & & .16 & 0.17 \\
\hline
\end{tabular}

Note. $* p<.05, * * p<.01, * * * p<.001$

Table 7

Results of Hierarchical Multiple Regression Analysis Predicting Stress Management

\begin{tabular}{|c|c|c|c|c|}
\hline Steps and Predictor Variables & $\mathrm{R}^{2}$ & $\Delta \mathrm{R}^{2}$ & $r$ & $B$ \\
\hline Step 1: & .05 & .05 & & \\
\hline Perception Management & & & .85 & .07 \\
\hline Overall GCI Score & & & .40 & .33 \\
\hline Step 2: & .07 & .02 & & \\
\hline Perception Management & & & .62 & .18 \\
\hline Overall GCI Score & & & .63 & .20 \\
\hline Studied Abroad in University & & & .22 & .18 \\
\hline
\end{tabular}

Note. $* p<.05, * * p<.01, * * * p<.001$ 


\section{Discussion}

In the global leadership literature, numerous competencies have been suggested as possible predictors of effective global leadership. Despite the many suggestions of what competencies may be predictive of global leadership, research validating the relationships between such competencies and global leadership outcomes or performance has been inadequate (Osland, 2015). While the field of global leadership first emerged as an unique field of literature in the 1990s, it was not until the last five years that research and interest in global leadership grew exponentially (Osland et al., p. 2). The reasons behind the surge in global organizations are numerous but include globalization, immigration, trade, outsourcing of jobs, and tax policies. Global leadership competencies or skills have been the most common topic in the global leadership literature to date (Osland et al., p. 2). This reflects the growing interest in identifying individuals with strong global leadership potential or finding ways to develop global leadership abilities and skills. An increased focus on developing socially responsible global leaders by scholars and companies has also contributed to the surge in global leadership research (Miska, Stahl, \& Mendenhall, 2013).

As the field of global leadership is still developing, there is a lack of options when it comes to validated tools for measuring global leadership. The most promising validated tool that exists is the Global Competencies Inventory (GCI) by The Kozai Group. While there are different studies validating the GCI for being able to predict various outcome variables, there was a lack of research on the GCI as a predictor of performance, behavioral, and cognitive outcomes. The main purpose of this study was to fill the gap in 
literature when it comes to scales that can reliably predict global leadership performance and cognitive outcomes. As the GCI was created using sound academic research on competencies related to effective global leaders, it was expected that the GCI could be used to predict a number of successful performance and behavioral outcomes.

The hypotheses in this study were partially supported. For the first hypothesis, although the overall global competencies score was not related to overall global leadership performance or demonstration of overarching global leadership behavior in the global leadership simulations, upon closer inspection there were significant relationships between the GCI and some of the performance outcomes. For example, both self and team ratings of a participant's overall contribution to the simulation were significantly related to the self-management and relationship-management dimensions of the GCI, along with being negatively correlated to social desirability. Self and team ratings of how well a participant was able to clearly communicate his or her ideas were significantly correlated with self-management. Thus, this study found partial support for the GCI as a predictor of performance outcomes. Several flaws with the methodology could be responsible for the other performance variables not being found to be significantly related and will be discussed in more detail.

The second hypotheses that the GCI is predictive of cognitive outcomes was not supported. Students' grades at the end of the semester were not significantly related to overall scores, or the perception-management dimension, which most closely measures cognitive abilities of the three GCI constructs. The third hypothesis proposed that various demographic variables could moderate the relationship between the GCI and different 
performance or cognitive outcomes. The results from the linear and multiple regression analyses in this study did not support this hypotheses. However, several demographic variables were found to have strong relationships with both the GCI and different performance outcomes.

\section{Theoretical Implications}

This study attempted to explore the predictive validity of the GCI, a reliable tool for measuring global leadership competencies that has been validated before (Stevens et al., 2014). One of the goals of this study was to see how well the GCI could predict different performance and cognitive outcomes that have been consistently linked to global leadership. Some of these performance outcomes included active listening, connecting and finding common ground, along with attitudinal outcomes such as nonjudgmentalness and tolerance for ambiguity. There is strong evidence supporting all of these measures as being related to global leadership (Stevens et al., 2014). Even though not every performance outcome was found to be significantly related to the GCI in this study, closer evaluation shows that this study still corroborates the current body of literature on global leadership. By demonstrating the predictive validity of the GCI when it comes to predicting certain global leadership performance outcomes, this study adds to the current literature on global leadership competencies that are predictive of effective global leadership. In addition, this study supports other studies showing the GCI as a reliable and valid tool for measuring global leadership.

The evaluation sheet that participants used to evaluate themselves and each other was created specifically to measure global leadership performance outcomes in the 
simulation (see Team Evaluation in Appendix). For self and peer evaluations, there were individual ratings on the evaluations sheets that were found to be significantly related to GCI dimensions. As described in the introduction, the self-management dimension mainly concerns two aspects of managing oneself: strength of personal identity and the ability to effectively manage one's emotions and stress (Bird et al., 2010; Mendenhall et al., 2008). Relationship-management encompasses a person's attitude towards the importance of relationships, such as his or her interest in and awareness of others, interaction style, along with his or her level of self-awareness (Bird et al., 2010; Mendenhall et al., 2008). This study's finding that these two dimensions predicted one's overall contribution to the global leadership simulation supports the existent current global leadership literature that stresses the importance of self-management and relationship-management when managing intercultural teams.

Self and team ratings of "ability to communicate ideas so that the other party fully understands what you have in mind" being significantly correlated with self-management competencies is consistent with the current literature in the importance of selfmanagement for global leadership. Being high in self-management can help individuals utilize more effective communication through better stress management, which then increases the individual's ability to deploy other global competencies effectively (Stevens et al., 2014). People higher in self-management are more resistant to "dysfunctional stressors that may influence people in their daily work and social life in intercultural interactions" (Mendenhall et al., 2008, p. 17). As global leadership can be particularly complex and stressful compared to domestic leadership, being more resistant to stress 
should improve one's communication skills in an intercultural setting (Mendenhall, 2012, Osland et al., 2007).

This study also found evidence supporting life events and global competencies as being significantly related to each other. Whether a student had studied abroad in university was related to how well that student appeared to handle stress. Being adept at handling stress is associated with effective global leadership (Darling \& Heller, 2011; Mendenhall et al., 2008). The amount of time a participant had lived in the United States had a significant relationship with relationship-management, suggesting that one's intercultural exposure is related to how well they maintain relationships with others. Individuals who had work experience that required them to either work on global virtual teams or travel internationally were higher in relationship-management and overall global leadership competencies. In addition, individuals with global virtual team experience also tended to score higher on perception-management, demonstrating higher cognitive processing abilities, which can be a necessity for working in a complex, computergenerated environment. The relationship between global leadership competencies and intercultural exposure is frequently documented in the global leadership literature (Caliguri \& Tarique, 2012; Tarique \& Caligiuri, 2009). Although some might argue that leadership abilities are innate or "leaders are born," it appears from the results of this study that the skills and competencies associated with global leadership can be developed over one's lifetime through intercultural interaction in places such as work and school. However, this study does not imply causality. It could be that global exposure causes individuals to develop stronger global leader competencies, but what? could also imply 
that individuals already high in intercultural competencies are more interested in pursuing global exposure, which should be investigated in future studies.

\section{Practical Implications}

Although the field of global leadership research has increased exponentially in the past five years, the field's growth is still hindered by a lack of clarity regarding construct definition. The absence of a universally agreed upon construct definition "may constitute the greatest obstacle to advancing the field"' (Osland et al., 2014, p. 3). This study attempted to clarify that confusion by settling on the definition by Mendenhall et al. (2012) and advocated by Osland et al. (2014) as being the most appropriate definition of global leadership. For the purpose of this study, global leadership is defined as "the process of influencing others from multiple cultures to adopt a shared vision through structures and methods that facilitate positive change while fostering individual and collective growth in a context characterized by significant levels of complexity, flow, and presence" (Osland et al., 2014, p. 5). Using the global leadership definition that the most prolific global researchers advocate will hopefully help future researchers overcome the obstacle of construct definition.

Another practical implication of this study is the applicability of this study's findings to many different settings, such as the workplace and the classroom. Although peers tended to rate each other quite highly as seen in the results section, the instances in which peers did not rate each other highly was when the individual did not participate or act engaged in the simulation. In undergraduate and even graduate classes, not everyone is fully engaged at the same rate (Chan \& McCroskey, 1987). This is why many 
American professors tend to include a participation portion in the students' final grade along with other incentives for students to be more engaged in class (Karp \& Yoels, 1976; Qi \& Weaver, 2005). Chan and McCroskey (1987) found that self-esteem and communication skills were higher in students who participated more in their undergraduate classes. Self-esteem and communication skills are measured under the self-management and relationship-management scales of the GCI, respectively. Since this sample consisted of undergraduate and graduate students, the study can be of use to those seeking to learn how those who participate differ from those who do not. Selfmanagement and relationship-management were both significantly related to a participant's overall contribution to the simulation, while the participant's "ability to communicate ideas so that the other party fully understands what he/she has in mind" was significantly related to self-management. Thus, one impact of this study is that it has uncovered some new uses for the GCI.

Another finding regarding variables related to one's overall contribution to the Alpha Beta negotiation is that it was negatively correlated with one's social desirability score. In practice, this means that the higher the participant scored on the social desirability scale, the less likely he or she was to actively contribute to the negotiation, perhaps out of shyness or fear of being judged. Companies seeking employees who will make a significant contribution at work should look for individuals who score high in self-management and relationship-management, but low in social desirability. Even for companies not seeking to expand internationally, the GCI could be useful for companies or organizations seeking ways to get their members more engaged or identify individuals 
who are ready to take on leadership roles. One cannot be a global leader if they are unwilling to participate or be engaged at work, demonstrated in this study by the participants who did not make an effort with helping their team negotiate in the Alpha Beta simulation. Workplaces seeking to identify individuals with global leadership potential should look for those who score lower in social desirability.

As discussed earlier, global leadership competencies can be learned, but it appears that life experience is an important source of intercultural knowledge. For example, participants who had studied abroad internationally were better at handling stress. In addition, those who had traveled internationally for work or been a part of a global virtual team scored significantly higher on the GCI. It may seem like "common sense" that individuals who travel more or have lived in more than one country are more worldly and might possess a stronger set of intercultural competencies, but common sense assumptions are often unsupported by research. This research suggests that employers seeking to hire employees who will be successful in an intercultural environment or even just effective contributors in the workplace should include considering the individual's prior intercultural exposure in their overall hiring assessment.

\section{Strengths, Limitations, and Future Research}

A key strength of this study, which distinguishes it from other studies in this field, is the wide variety and range of variables analyzed. There was a diverse range of variables related to performance, behavioral, attitudinal, and cognitive outcomes. This study was also able to identify some of these as being related to the GCI, while explaining why other variables may not be related. To the author's best knowledge, 
previous validation studies of the GCI did not utilize as broad a range of outcome variables. For example, Furuya, Stevens, Bird, Oddou, and Mendenhall (2009) found that the GCI did significantly predict peer ratings of job performance on expatriate assignments, but not managerial ratings of job performance. By analyzing a wide range of outcome variables that should theoretically be related to the GCI, this study also uncovered useful information about how individuals who contribute more in the classroom and/or workplace may differ from those who do not make as much of a contribution. This was found in the finding that for both self and peer evaluations there was a significant, positive relationship between one's overall contribution to the negotiation and the self-management and relationship-management dimensions of the GCI. In addition, this study's findings had higher reliability from having multiple sources for ratings - self, peer, and graduate evaluators, making the findings where self and peer ratings corroborated each other even stronger. However, having the participants as a source of ratings ended up being a limitation of the study.

Limitations. One of the major limitations of this study was the fact that the sample consisted of undergraduate and graduate students from one university located on the West coast of the United States. The sample was diverse when it came to ethnicity, nationality, age, and gender. However, college students may be lacking in work experience when compared to the general population. For the variable as to whether students had ever held a job where they had to travel internationally, $11.60 \%$ reported having no work experience at all. However, despite the sample being limited to university students, there was still enough of a range in work experience for several of the work 
demographic variables to be found significantly related to GCI scores. This is because while having a sample consisting of mainly undergraduate and graduate students from one university can imply a relatively homogeneous population, one professor from the global leadership department describes the university's student body as an anomaly in terms of diversity in age, gender, ethnicity, and nationality. For example, the ages in this study ranged from 19 to 53 , with $76.38 \%$ of the sample being international students, expatriates, or U.S. nationals who had not been born in the United States. Also, $88.40 \%$ of the sample had work experience. Many of the students at the sampled university are older and have more work experience compared to students at colleges and universities with more traditionally homogenous student demographics. While the sample was not as representative of the general population as a random sample would have been, it was still relatively diverse.

Despite the fairly diverse student body, the main weakness of having only college students included in the sample is having them evaluate themselves. As most college students are not experts in the field of global leadership they may lack key construct knowledge required for rating themselves and peers on complex global leadership constructs. For example, when participants were asked to rate themselves on global leadership knowledge on a scale from 1 to 5, with 1 being "novice" and 5 being "expert," just $1.1 \%$ of students rated themselves as having expert knowledge of global leadership prior to taking the course. This could be the possible explanation behind why variables that should theoretically be related to global leadership competencies such as biculturalism and interacting with a diverse group of people at work were not related to 
the GCI. Students may not understand that cultural diversity is not the same as ethnic diversity (Watson, Kumar, \& Michaelsen, 1993). From reading the answers of participants who claimed to be from a bicultural background, they seemed to be confused as to what biculturalism entails. Some of the sample answers included "Black," "White," or included responses about their family immigrating to the United States from an European country during the 1800s, when they are essentially American and not from a multicultural background. There was a surprisingly high number of students who answered "Black," "White," or "Hispanic" when asked what nationality they are, demonstrating that many of the participants in this sample were confused as to what nationality constitutes versus ethnicity. This same reasoning could apply to the question about diverse work groups. Students may be confusing ethnic/racial diversity with cultural diversity. A more experienced sample may have provided responses that yielded significant results. In future studies of this nature it will likely be important to be highly specific when giving directions and to provide specific examples so there is less confusion around cultural terminology.

This same limitation of college students doing the evaluations could also have impacted why more of the performance and behavioral outcomes were not significantly predicted by the GCI. Although, the students were taking a course on global leadership, they still may have lacked experience needed to evaluate themselves and peers on more complex global leadership constructs such as tolerance for ambiguity and code-switching, hence, these variables were found unrelated to the GCI, despite an abundance of research supporting them as important global leadership outcomes. Despite the course teaching 
students these global leadership concepts, $49.5 \%$ of students had still rated themselves a "2" or lower on their prior global leadership knowledge on a five-point scale. While students may thoroughly understand what the construct means, they may not know what to observe when conducting the evaluations. Future studies can address this issue of participant construct knowledge by making a more specific evaluation rubric that has precise examples of what behaviors constitute a "1" score versus a "2" or " 3 ".

The other limitation of having students evaluate the performance of themselves and others is rater bias. Students might have been reluctant to give themselves or their peers low scores. As a result scores were heavily skewed toward positive ratings across the board for self and peer evaluations. Having mostly high ratings also greatly affected the variance of the scores. With very little variance, it is not surprising that most of the performance and behavioral variables were not significant. This lack of variance and skew towards high scores seems to be a halo effect. The halo effect is a common cognitive bias in which a person's overall impressions of a person affect the observer's feelings and ratings about other aspects of that person, and can cause ambiguous or neutral traits to be viewed in a positive light, particularly when doing performance evaluations (Bormon, 1975). This case of ambiguous or neutral behavior being ranked positively was present in this study. As mentioned earlier, some participants did not contribute to the negotiations or speak at all, yet were rated very highly, as they had not done anything outwardly negative. The fact that participants are not required to speak or contribute at all during the simulations was another weakness. It likely made it difficult for students to rate peers who had demonstrated completely neutral and ambiguous 
behavior. To eliminate the study's halo effect, the author suggests allowing students to complete the evaluations at home, or somewhere more private, rather than in the classroom surrounded by their peers. This might help prevent the participant's overall feelings of that person and social desirability to cause them to give unfairly high ratings. For the issue of participants not participating at all, the evaluation sheet should include specific instructions to rate participants only on behavior that was observed and to assign an "N/A" to participants who did not demonstrate negative or positive behavior. It should be noted that the halo effect was especially present in evaluations completed by undergraduate students. The peer evaluations completed by graduate students appeared to have greater variability, as graduate students may be more knowledgeable about global leadership competencies and less reluctant to give their peers varied scores. Future studies may consider only using peer evaluations from graduate students in order to obtain significant results.

Another noteworthy limitation is that some variables were limited by sample size, due to some participants not answering all survey questions. In addition, there were only 42 evaluations completed by graduate students for the Alpha Beta negotiation. Future studies using larger samples will likely have different results and a more diverse range of answers. The final limitation of this study that should be addressed concerns why perception-management and one's overall global competency score were not predictive of the cognitive outcome variable, student grades. Since the sample was a mix of undergraduate and graduate students, the grading system might have been skewed. As is typical with U.S. graduate school programs, grades tend to have a disproportionate 
amount of As and Bs. Anything below a B is rarely earned by graduate students, according to one of the professor's working in the university's business department, due to the caliber of the students and the school's more rigorous selection process for graduate students. The limited range in graduate student grades might have contributed to the GCI being found not significantly related to student grades. If future studies choose to include both undergraduate and graduate students, the grades for graduate students need to be coded differently to reflect the lower variance. For example, a graduate "C" could be coded as the equivalent of an " $F$ " for undergraduates in order to get significant results that are not skewed by disproportionately high graduate student grades.

Another reason why grades were not significantly related to the GCI is because course grades may not be a purely cognitive measure, as other constructs not necessarily measured by the GCI such as conscientiousness and self-control may factor into grades (Lounsbury, Sundstrom, Loveland, \& Gibson, 2003; Tangney, Baumeister, \& Boone, 2004). When it comes to construct representation in this study, is also important to note that all the constructs of the GCI were not intended to be covered by the simulation. There are seventeen subdimensions on the GCI and not all are represented in the 30minute Alpha Beta negotiation. For example, the GCI sub-dimension interest flexibility, mainly applies to expatriates who are adjusting to life in a new country and would not be measured during the Alpha Beta negotiation. Thus, this is another explanation behind why there were not more significant relationships found in this study between the GCI and outcome measures. 


\section{Conclusion}

Globalization, along with societal changes and technological advances make it more necessary than ever for organizations to have employees who display intercultural competencies. There is a much higher demand for global leaders than there are individuals who qualify as effective global leaders (WEF, 2013; Osland et al., 2014; PriceWaterhouseCoopers, 2014). Analyzing the competencies and behavioral practices that distinguish successful global leaders can help bring additional clarity to this complex, maturing field through the development of the GCI. Having a tool that can reliably predict individuals that will make successful global leaders will help organizations select the most qualified candidates for global leadership positions. Greater knowledge of global leadership competencies will allow for the successful development of programs to train individuals to be more effective global leaders. Being able to measure global leadership competencies will also allow organizations to identify areas where employees or members can improve in a wide range of intercultural competencies, leading to more favorable outcomes for both the organization and the employees. 


\section{References}

Albrecht, T. L., \& Hall, B. J. (1991). Facilitating talk about new ideas: The role of personal relationships in organizational innovation. Communications Monographs, 58, 273-288.

Arnold, H. J. (1982). Moderator variables: A clarification of conceptual, analytic, and psychometric issues. Organizational Behavior and Human Performance, 29, 143174.

Aycan, Z., \& Kanungo, R. N. (1997). Current issues and future challenges in expatriate management. New Approaches to Employee Management, 4, 245-260.

Bandura, A. (1977). Self-efficacy: toward a unifying theory of behavioral change. Psychological Review, 84, 191.

Beretvas, S. N., Meyers, J. L., \& Leite, W. L. (2002). A reliability generalization study of the Marlowe-Crowne Social Desirability Scale. Educational and Psychological measurement, 62, 570-589.

Bhaskar-Shrinivas, P., Harrison, D. A., Shaffer, M. A., \& Luk, D. M. (2005). Input-based and time-based models of international adjustment: Meta-analytic evidence and theoretical extensions. Academy of Management Journal, 48, 257-281.

Bird, A., Mendenhall, M., Stevens, M. J., \& Oddou, G. (2010). Defining the content domain of intercultural competence for global leaders. Journal of Managerial Psychology, 25, 810-828.

Bird, A., Osland, J. S., \& Lane, H. W. (2004). Global competencies: An introduction. The Blackwell Handbook of Global Management: A Guide to Managing Complexity, 57-80.

Black, J. S., Mendenhall, M., \& Oddou, G. (1991). Toward a comprehensive model of international adjustment: An integration of multiple theoretical perspectives. Academy of Management Review, 16, 291-317.

Black, J. S., Morrison, A. J., \& Gregersen, H. B. (1999). Global Explorers: The Next Generation of Leaders. Psychology Press.

Borman, W. C. (1975). Effects of instructions to avoid halo error on reliability and validity of performance evaluation ratings. Journal of Applied Psychology, 60, 556.

Burke, V., \& Collins, D. (2005). Optimising the effects of leadership development programmes: A framework for analysing the learning and transfer of leadership skills. Management Decision, 43, 975-987. 
Caligiuri, P., \& Tarique, I. (2012). Dynamic cross-cultural competencies and global leadership effectiveness. Journal of World Business, 47, 612-622.

Caligiuri, P., \& Tarique, I. (2014). Individual-level accelerators of global leadership development. Advances in Global Leadership (Advances in Global Leadership, Volume 8) Emerald Group Publishing Limited, 8, 251-267.

Chan, B., \& McCroskey, J. C. (1987). The WTC scale as a predictor of classroom participation. Communication Research Reports, 4, 47-50.

Chen, G.M. and Starosta, W.J. (1996), "Intercultural communication competence: a synthesis." Communication Yearbook, Vol. 19, pp. 353-83.

Chien, T. C., \& McLean, G. N. (2011). Intercultural training for US business expatriates in Taiwan. Journal of European Industrial Training, 35, 858-873.

Chiang, S. (2015). Cultural adaptation as a sense-making experience: International students in China. Journal of International Migration and Integration, 16, 397-413. doi:http://dx.doi.org/10.1007/s12134-014-0346-4

Crossman, J., \& Bordia, S. (2008). Emerging issues in international education in business contexts. Journal of International Education in Business, 1, 2-14. doi:http://dx.doi.org/10.1108/18363261080001590

Darling, J. R., \& Heller, V. L. (2011). The key for effective stress management: Importance of responsive leadership in organizational development. Organization Development Journal, 29, 9-26.

Deardorff, D. (2004), “The identification and assessment of intercultural competence as a student outcome of internationalization at institutions of higher education in the United States", PhD dissertation, North Carolina State University, Raleigh, NC.

Dimitrov, N., Dawson, D. L., Olsen, K. C., \& Meadows, K. N. (2014). Developing the Intercultural Competence of Graduate Students. Canadian Journal of Higher Education, 44, 86-103.

Dinges, N.G. and Baldwin, K.D. (1996), "Intercultural competence: a research perspective", in Landis, D. and Bhagat, R.S. (Eds), Handbook of Intercultural Training, 2nd ed., pp. 106-23.

Freedman, D. A. (2009). Statistical models: Theory and Practice. Cambridge University Press. 
Furuya, N., Stevens, M. J., Bird, A., Oddou, G., \& Mendenhall, M. (2009). Managing the learning and transfer of global management competence: Antecedents and outcomes of Japanese repatriation effectiveness. Journal of International Business Studies, 40, 200-215.

Gertsen, M.C. (1990), "Intercultural competence and expatriates", International Journal of Human Resource Management, Vol. 3, pp. 341-62. 109.

Ghemawat, P. (2012). Developing global leaders. McKinsey Quarterly, 3, 100-

Graham, J. L. (1983). Brazilian, Japanese, and American business negotiations. Journal of International Business Studies, 14, 47-61.

Harrison, D. A., \& Shaffer, M. A. (2005). Mapping the criterion space for expatriate success: task-and relationship-based performance, effort and adaptation. The International Journal of Human Resource Management, 16, 1454-1474.

Hechanova, R., Beehr, T. A., \& Christiansen, N. D. (2003). Antecedents and consequences of employees' adjustment to overseas assignment: a meta-analytic review. Applied Psychology, 52, 213-236.

Herman, J. L., Stevens, M. J., Bird, A., Mendenhall, M., \& Oddou, G. (2010). The tolerance for ambiguity scale: Towards a more refined measure for international management research. International Journal of Intercultural Relations, 34, 58.

Hong, L., \& Page, S. E. (2004). Groups of diverse problem solvers can outperform groups of high-ability problem solvers. Proceedings of the National Academy of Sciences of the United States of America, 101, 16385-16389.

Ivanova, V., \& Arenas, A. (2014). E-Leadership Skills for SMEs - Challenges to the Universities Economic and Social Development: Book of Proceedings, 256.

Jaccard, J., \& Turrisi, R. (2003). Interaction effects in multiple regression (No. 72). Sage.

Jokinen, T. (2005). Global leadership competencies: a review and discussion. Journal of European Industrial Training, 29, 199-216.

Karp, D. A., \& Yoels, W. C. (1976). The college classroom: Some observations on the meanings of student participation. Sociology \& Social Research.

Kayworth, T. R., \& Leidner, D. E. (2002). Leadership effectiveness in global virtual teams. Journal of Management Information Systems, 18, 7-40. 
Kedia, B. L., \& Mukherji, A. (1999). Global managers: Developing a mindset for global competitiveness. Journal of World Business, 34, 230-251.

Keith, T. Z. (2014). Multiple Regression and Beyond: An Introduction to Multiple Regression and Structural Equation Modeling. Routledge.

Keung, E. K., \& Rockinson-Szapkiw, A. (2013). The relationship between transformational leadership and cultural intelligence. Journal of Educational Administration, 51, 836-854. doi:http://dx.doi.org/10.1108/JEA-04-2012-0049

Konopaske, R., Mendenhall, M., \& Thomason, S. (2009, August). Toward a typology of the expatriate construct. In Academy of Management Meetings. August (Vol. $10)$.

Levy, O., Beechler, S., Taylor, S., \& Boyacigiller, N. A. (2007). What we talk about when we talk about 'global mindset': Managerial cognition in multinational corporations. Journal of International Business Studies, 38, 231-258.

Leiba-O'Sullivan, S. (1999). The distinction between stable and dynamic crosscultural competencies: Implications for expatriate trainability. Journal of International Business Studies, 709-725.

Lounsbury, J. W., Sundstrom, E., Loveland, J. M., \& Gibson, L. W. (2003). Intelligence, "Big Five" personality traits, and work drive as predictors of course grade. Personality and Individual Differences, 35, 1231-1239.

Maznevski, M., Stahl, G. K., \& Mendenhall, M. E. (2013). Thematic Issue: Towards an Integration of Global Leadership Practice and Scholarship: Repairing Disconnects and Heightening Mutual Understanding Introduction.

Mendenhall, M., \& Oddou, G. (1985). The dimensions of expatriate acculturation: A review. Academy of Management Review, 10, 39-47.

Mendenhall, M., \& Osland, J. S. (2002, June). An overview of the extant global leadership research. In Symposium presentation, Academy of International Business, Puerto Rico, June.

Mendenhall, M. E., \& Osland, J. (2012). Global leadership: Research, Practice, and Development. Routledge.

Mendenhall, M.E., Reiche, B.S., Bird, A., \& Osland, J.S. (2012). Defining the 'global' in global leadership. Journal of World Business, 47(4): 493-5. 
Mendenhall, M.E., Stevens, M.J., Bird, A. \& Oddou, G.R. (2010). Specification of the Content Domain of the Global Competencies Inventory (GCI). The Kozai Working Paper Series 1, 1-42.

Miska, C., Stahl, G. K., \& Mendenhall, M. E. (2013). Intercultural competencies as antecedents of responsible global leadership. European Journal of International Management, 7, 550-569.

Mol, S. T., Born, M. P., Willemsen, M. E., \& Van Der Molen, H. T. (2005). Predicting expatriate job performance for selection purposes A quantitative review. Journal of Cross-Cultural Psychology, 36, 590-620.

Molinsky, A . (2007) Cross-cultural code-switching: The psychological challenges of adapting behaviour in foreign cultural interactions. Academy of Management Review, 32, 622-640.

Mukherjee, S., \& Ramos-Salazar, L. (2014). "Excuse us, your manners are missing!" the role of business etiquette in today's era of cross- cultural communication. TSM Business Review, 2, 18-28.

Mumford, T. V., Campion, M. A., \& Morgeson, F. P. (2007). The leadership skills strataplex: Leadership skill requirements across organizational levels. Leadership Quarterly, 18, 154.

Mumford, M. D., Zaccaro, S. J., Connelly, M. S., \& Marks, M. A. (2000). Leadership skills: Conclusions and future directions. The Leadership Quarterly, 11, 155170.

Osland, J. S. (2013). The multidisciplinary roots of global leadership. Global leadership: Research, Practice, and Development, 21-39.

Osland, J. S., \& Bird, A. L. L. A. N. (2013). Process models of global leadership development. Global Leadership: Research, Practice and Development, 97-112.

Osland, J. S., Li, M. \&Wang, Y. (2014). Introduction: The State of Global Leadership Research. In Osland, J. S., Li, M., \& Wang, Y. (Eds). Advances in global leadership (Vol. 8) (1-16). Bingley, UK: Emerald Group Publishing.

Osland, J., Oddou, G., Bird, A., \& Osland, A. (2013). Exceptional global leadership as cognitive expertise in the domain of global change. European Journal of International Management, 7, 517-534.

PriceWaterhouseCoopers's Annual Global CEO Survey. (2014). Fit for the Future: Capitalising on Global Trends. PriceWaterhouseCoopers. 
Qi, J., \& Weaver, R. R. (2005). Classroom organization and participation: College students' perceptions. The Journal of Higher Education, 76, 570-601.

Reiche, B. S., Bird, A., Mendenhall, M. E., \& Osland, J. (2015, January). The Conceptual Basis for a Global Leadership Typology. In Academy of Management Proceedings (Vol. 2015, No. 1, p. 10907). Academy of Management.

Ruben, B. D., \& Kealey, D. J. (1979). Behavioral assessment of communication competency and the prediction of cross-cultural adaptation. International Journal of Intercultural Relations, 3, 15-47. Education.

Schneider, S. C., \& Barsoux, J. L. (2003). Managing Across Cultures. Pearson

Selmer, J. (2001). Expatriate selection: back to basics. International Journal of Human Resource Management, 12, 1219-1233.

Snyder, M. (1974). Self-monitoring of expressive behavior. Journal of Personality and Social Psychology, 30, 526.

Steers, R. M., Sanchez-Runde, C., \& Nardon, L. (2012). Leadership in a global context: New directions in research and theory development. Journal of World Business, 47, 479-482.

Stevens, M., Bird, A., Mendenhall, M. E. \& Oddou, G. (2014). Measuring Global Leader Intercultural Competency: Development and Validation of the Global Competencies Inventory (GCI). In Osland, J. S., Li, M., \& Wang, Y. (Eds). Advances in global leadership (Vol. 8) (115-154). Bingley, UK: Emerald Group Publishing.

Tangney, J. P., Baumeister, R. F., \& Boone, A. L. (2004). High self-control predicts good adjustment, less pathology, better grades, and interpersonal success. Journal of Personality, 72, 271-324.

Tansley, C., \& Newell, S. (2007). Project social capital, leadership and trust. Journal of Managerial Psychology, 22, 350-368.

doi:http://dx.doi.org/10.1108/02683940710745932

Takeuchi, R., Tesluk, P. E., Yun, S., \& Lepak, D. P. (2005). An integrative view of international experience. Academy of Management Journal, 48, 85-100.

Tarique, I., \& Caligiuri, P. (2009). The role of cross-cultural absorptive capacity in the effectiveness of in-country cross-cultural training. International Journal of Training and Development, 13, 148-164. 
Van de Mortel, T. F. (2008). Faking it: social desirability response bias in selfreport research. The Australian Journal of Advanced Nursing. 25, 40-48.

VanderPal, G. (2014). Global leadership, IQ and global quotient. Journal of Management Policy and Practice, 15, 120-134.

Watson, W. E., Kumar, K., \& Michaelsen, L. K. (1993). Cultural diversity's impact on interaction process and performance: Comparing homogeneous and diverse task groups. Academy of Management Journal, 36, 590-602. 


\section{ALPHA BETA NEGOTIATION SIMULATION}

\section{INTRODUCTION AND NEGOTIATION SKILL COMPONENTS}

In this simulation, you will be negotiating an agreement between your company and a foreign company. You will be given a role to learn and time to plan your negotiation strategy with a small assigned team. Then you will have time to negotiate with a team from a different country. You will receive peer feedback on your overall contribution and involvement in the simulation and, specifically, on the following five negotiation skills. The first three of these skills reinforce many of the intercultural competence skills we have practiced throughout the course.

1. To decode and understand the other party's (in the negotiation) behavior from their perspective. To practice empathy and see the world as other people see it.

2. To be sensitive to the other party's cultural background and constraints and adjust your behavior accordingly.

3. To manage stress and to cope with ambiguous situations, as well as unpredictable demands.

4. To be persuasive and demonstrate the advantages of your negotiation proposals so that the other party is willing to change their stance.

5. To communicate your ideas so that the other party will fully understand what you have in mind and not be offended.

\section{NEGOTIATION SIMULATION -- STUDENT INSTRUCTIONS}

1. Assign negotiation role

2. Carefully read your instruction sheet to yourself; there will actually be a comprehension test to help you be well prepared. :) (5-8 minutes)

3. Assignment to a negotiation team. (The Alphans will stay in the incubator classroom; the Betans will go to their assigned negotiation room.) (5 minutes)

4. Begin behaving in accordance with your culture's negotiation style. Practice so it becomes natural as your 3-person team jointly takes the Team Quiz (10 minutes)

5. Prepare the Team Negotiation Preparation Worksheet (20 minutes)

6. The Alphans will be given a room assignment and join their Betan counterparts. (5 minutes)

7. Introduce yourselves to the other team and carry out the first half of the negotiation. Your goal in the negotiation is to come to a good agreement that is reasonable for both sides on all four issues listed on your Negotiation Agreement and at the end of your simulation instructions. (15 minutes for first half of negotiation)

8. At the 15-minute mark, open Envelope \#1 and INDIVIDUALLY fill out the Process Check Sheet without talking. Place it back in the envelope and seal the envelope. (5 minutes)

9. Spend the next 5 minutes regrouping with your subgroup (one team should step into the hallway so their talk is private). Talk with your two teammates about how you could improve the negotiation and your strategy. (5 minutes)

10. Complete the last 15 minutes of the negotiation (set a timer and don't go over 15 minutes). You have 5 more minutes to write up your agreement and do peer evaluations. On the orange Negotiation Agreement clipped to Envelope \#2 found on your table, write down the terms of your agreement on the four issues and have each person sign to indicate their approval. Place it in Envelope \#2. Then fill out individually without talking the Team Evaluation for everyone 
with whom you negotiated and put your form into the Envelope \#2 Team Evaluation/

Negotiation Agreement and seal. Next quickly return to the incubator classroom and hand in your two team envelopes and be seated. (20 minutes)

11. Be back in the incubator classroom by $9: 50 /$ (unless given a different time) ready to debrief the simulation. (10 minutes)

NEGOTIATION SIMULATION INSTRUCTIONS FOR FACILITATORS

\section{MATERIALS:}

ALPHA BETA NEGOTIATION SIMULATION instruction sheet for each student

Negotiation Roles (2 sets in different colors; 1 dual sheet for all)

Team Room assignments on one sheet for each student with a map

Team Quiz for each student

Process Checks (6 in each envelope) in 7-8 Envelopes, labeled "\#1 Process Check", placed on each negotiation table

Negotiation Agreement placed on each negotiation table (7-8 copies)

Team Evaluations - 6 clipped to 7-8 envelopes, labeled "\#2 Team Evaluations/Negotiation

Agreement"; 1 for each facilitator to fill out while observing, and another 1 per student for the compilation of their feedback. $=$

FLIP cameras fully charged and tripods ( 1 per team plus one extra in case of problems)

Extra camera batteries

\section{Negotiation Rooms:}

Each room should be set up with a small negotiation table with 3 chairs on each side. Each table should have:

One orange Negotiation Agreement

\#1 Envelope with 6 Process Checks inside (students should not look at the Process Checks until 15 minutes into the negotiation).

\#2 Envelope with 6 Team Evaluations clipped to the outside

FLIP cameras on tripods ready to go - placed so that all students can be seen

\section{THINGS TO LOOK OUT FOR AS A FACILITATOR}

Make sure the cameras are turned on and off at the appropriate moment (on button on the side and push the big red button to start and stop recording)

If they hesitate to begin negotiating, politely inform them that their first fifteen minute negotiation starts immediately and their time is limited. Otherwise, try not to intervene. They might need to be reminded that one team can go outside during the 5 minute regrouping, but see if they can be responsible for that themselves.

Make sure they don't look at the Process Checks until 15 minutes into the negotiation and then make sure they are filled out individually without talking, placed back into the envelope, and sealed.

At the end of the negotiation they need to jointly fill out and sign the Negotiation Agreement and fill out their Team Evaluations individually without talking about them.

Please help get them back to the classroom by the assigned time

Turn off the camera at the end of the negotiation (on/off button on the side)

Make sure they hand in the envelopes and return on time. 


\section{PREPARATION PLAN}

Remember to act like your culture from now on so that you learn your negotiation style and show consistent behavior to the other team. Discuss this as a team.

1. What are your goals in this negotiation? Your priorities?

2. What do you think will be the goals of the other party? What are their priorities?

3. How are you going to figure out their values, needs, etc.?

4. What information do you need from them?

5. You know they are from a different culture. How are you going to behave?

6. How will you open the negotiation?

7. What is your initial position or offer?

8. What concessions are you willing to make?

Good luck!

Name: 


\section{PROCESS CHECK}

Please answer this individually without talking to other students.

1. How is the negotiation style of the other team culturally different from your own?

2. Based on what you have observed, how do you need to adapt your own style to be successful negotiating with them?

3. a. Which of Adler's Global Strategic Options (see below) is your team using?

b. Which option is the other negotiating team using?

"My Culture's Way"

Cultural Dominance

Cultural Synergy

Cultural Compromise

Cultural Avoidance

Cultural Accommodation

"Their Culture's Way"

4. What's the biggest problem you see in your negotiation to this point?

5. How are you going to fix it?

P.S. When you huddle with your own negotiation time, how can you stay true to your culture's negotiating style AND reach cultural synergy and a win-win agreement?

Without looking at anyone else's Process Check, please put the $m$ all into Envelope \#1 and seal it. 


\section{NEGOTIATION AGREEMENT}

We, the undersigned members of both the Alpha and Beta negotiating teams, agree to the following terms.

1. Number of different Models:

2. Number of Beta Inc. units to be imported and/or produced under license by Alpha during each year:

3. The matter of technology sharing (Beta access to Alpha proprietary R\&D advances):

4. Royalty rate (percentage on gross sales):

Signatures

ALPHA MEMBERS

BETA MEMBERS 


\section{TEAM EVALUATION}

Name:

Negotiation Team:

The "other party" below refers to the other negotiating team. Please evaluate objectively in a professional manner each member of the negotiation teams, including yourself, using these criteria: $1=$ poor $2=$ average $3=$ good

\begin{tabular}{|c|c|c|c|c|c|c|}
\hline $\begin{array}{l}\text { ALPHA } \\
\text { NAMES }\end{array}$ & $\begin{array}{l}\text { Overall } \\
\text { contribution } \\
\text { to the } \\
\text { negotiation } \\
\text { simulation }\end{array}$ & $\begin{array}{l}\text { Ability to decode } \\
\text { and understand } \\
\text { the other party's } \\
\text { behavior }\end{array}$ & $\begin{array}{l}\text { Ability to modify } \\
\text { and adjust their } \\
\text { behavior to the } \\
\text { other party's } \\
\text { cultural } \\
\text { background and } \\
\text { constraints } \\
\text { (code switching) }\end{array}$ & $\begin{array}{l}\text { Ability to } \\
\text { manage stress } \\
\text { and cope with } \\
\text { ambiguous } \\
\text { situations and } \\
\text { unpredictable } \\
\text { demands }\end{array}$ & $\begin{array}{l}\text { Demonstrates the } \\
\text { advantages of } \\
\text { their negotiation } \\
\text { proposals and } \\
\text { can thereby } \\
\text { persuade the } \\
\text { other party to } \\
\text { change its stance }\end{array}$ & $\begin{array}{l}\text { Ability to } \\
\text { communicate } \\
\text { ideas so that the } \\
\text { other party fully } \\
\text { understands } \\
\text { what you have in } \\
\text { mind }\end{array}$ \\
\hline 1. & & & & & & \\
\hline 2. & & & & & & \\
\hline 3. & & & & & & \\
\hline $\begin{array}{l}\text { BETA } \\
\text { NAMES }\end{array}$ & & & & & & \\
\hline 1. & & & & & & \\
\hline 2. & & & & & & \\
\hline 3. & & & & & & \\
\hline
\end{tabular}


GLLAB BEHAVIORAL CODING WORKSHEET

\begin{tabular}{|c|c|c|c|c|c|}
\hline COMPETENCIES & POOR & FAIR & EXCELLENT & $\begin{array}{l}\text { BEHAVIORAL } \\
\text { EXAMPLES }\end{array}$ & COMMENTS \\
\hline Active listening skills & $\begin{array}{l}\text { Showed little } \\
\text { interest in what } \\
\text { the other } \\
\text { person was } \\
\text { saying. Spoke } \\
\text { over the other } \\
\text { person. Self- } \\
\text { focused. }\end{array}$ & $\begin{array}{l}\text { Listened to the } \\
\text { other person's } \\
\text { views, but did not } \\
\text { actively and } \\
\text { constructively } \\
\text { participate in the } \\
\text { conversation. }\end{array}$ & $\begin{array}{l}\text { Listened carefully, } \\
\text { paraphrased, reflected } \\
\text { underlying implications } \\
\text { and feelings, asked } \\
\text { appropriate questions }\end{array}$ & & \\
\hline Being non-judgmenlal & $\begin{array}{l}\text { Made } \\
\text { judgmental } \\
\text { remarks; } \\
\text { looked } \\
\text { disapproving. }\end{array}$ & $\begin{array}{l}\text { Demonstraled } \\
\text { judgment in body } \\
\text { language, but not } \\
\text { through verbal } \\
\text { expression. }\end{array}$ & $\begin{array}{l}\text { No judgment manifested } \\
\text { in any way; open-minded }\end{array}$ & . & \\
\hline $\begin{array}{l}\text { Accurately read cues and } \\
\text { decode other's cultural } \\
\text { behavior }\end{array}$ & $\begin{array}{l}\text { Did not pick up } \\
\text { on cues. } \\
\text { Made no } \\
\text { attempt to } \\
\text { understand the } \\
\text { other culture. }\end{array}$ & $\begin{array}{l}\text { Seemed open to } \\
\text { the other culture, } \\
\text { but showed little } \\
\text { comprehension of } \\
\text { it. }\end{array}$ & $\begin{array}{l}\text { Picked up on cues and } \\
\text { demonstrated } \\
\text { understanding of the } \\
\text { other person's cultural } \\
\text { behavior. }\end{array}$ & 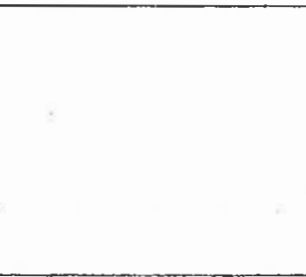 & \\
\hline $\begin{array}{l}\text { Appropriately adapt } \\
\text { communication style and } \\
\text { behavior, code-switch" }\end{array}$ & $\begin{array}{l}\text { Made little or } \\
\text { no change to } \\
\text { his or her } \\
\text { communication } \\
\text { style. }\end{array}$ & $\begin{array}{l}\text { Made some } \\
\text { changes to his or } \\
\text { her communication } \\
\text { style, but still } \\
\text { experienced some } \\
\text { barriers to } \\
\text { communication. }\end{array}$ & $\begin{array}{l}\text { Utilized knowledge of the } \\
\text { other culture to effectively } \\
\text { communicate with the } \\
\text { other person. }\end{array}$ & . & \\
\hline
\end{tabular}

GLLab - Intercultural Competence, Global Leadership Advancement Center, SJSU 
?

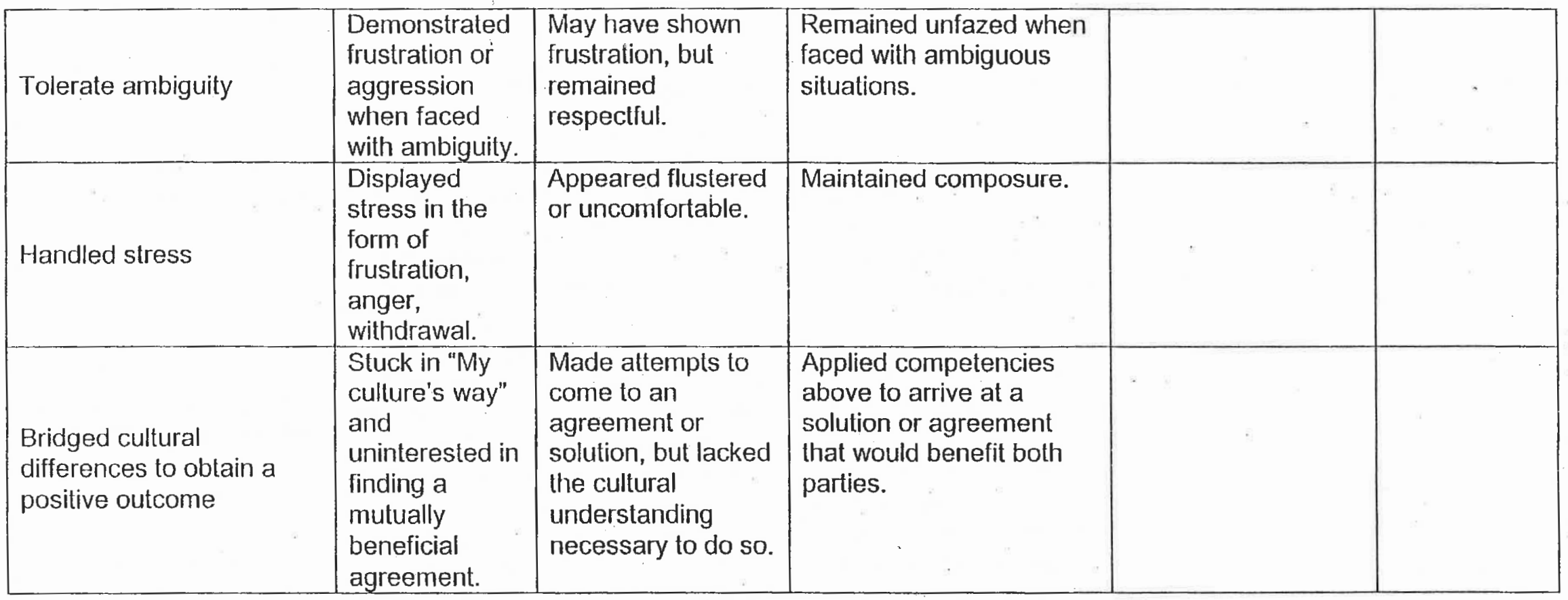

GLLab - Intercultural Competerice, Global Leadership Advencement Center, SJSU 